\title{
MINAS DE HIERRO Y SIDERURGIA EN EL ENTORNO DEL MONCAYO EN LA EDAD MEDIA
}

\author{
IRON MINING AND IRON INDUSTRY IN THE SURROUNDINGS \\ OF MONCAYO IN THE MIDDLE AGES
}

JuAn José Morales GóMEZ

Gobierno de Aragón. Archivos

\begin{abstract}
Resumen: Más allá de la simple existencia, se sabía muy poco de la explotación medieval de los yacimientos férricos del Moncayo. El presente estudio demuestra que se remonta, de forma probada, al siglo XIII, aunque es muy posible que sus raíces se retrotraigan, como mínimo, al siglo anterior. Reproduciendo con notable fidelidad los grandes flujos de avance y retroceso de la minería europea e integrando las novedades tecnológicas en el ámbito de la forja que iban sucediéndose, la producción de hierro del Moncayo alcanza cotas interesantes a fines de la Edad Media. Estos resultados, aunque modestos en comparación con los de las grandes áreas férricas del Cantábrico, debieron tener un efecto visible en la economía regional.
\end{abstract}

Palabras clave: hierro, siderurgia, minería, Moncayo, Aragón.

\begin{abstract}
We have few information about working on iron beds in the area of mount Moncayo in the Middle Ages, except for its only existence. This study shows that those works can be proved for XIIIth century and, perhaps they have some roots, at least, in the previous century. The iron production in mount Moncayo reaches interesting levels at the end of Middle Ages. It reproduces accurately the movements of European mining, going ahead or going back, and it integrates technological advances that were made in industrial sector. These results, even though they seem not very big, - if we compare them with the rest of great mining areas in the Cantabric coast - , must have been quite profitable for the local economy.
\end{abstract}

Keywords: Iron, iron industry, mining, Moncayo, Aragon. 


\section{Introducción}

El macizo del Moncayo se localiza entre Castilla y Aragón, muy cerca de la confluencia de las fronteras de estos antiguos reinos con Navarra, marcando la divisoria entre la cuenca hidrográfica del Duero y la del Ebro. En este territorio y su entorno inmediato - las comarcas de Tarazona, Campo de Borja, Tierras de Agreda y Aranda - las mineralizaciones ferruginosas son muy abundantes. Las prospecciones mineras y metalogenéticas de nuestros días las detectan, en mayor o menor grado, prácticamente por todas partes (Mata-Perelló, 1989; Carmona Pérez et alii, 1989; VV.AA., 1994: 146-148; etc.). Aunque, por lo común, son de poca entidad y en la actualidad carecen casi todas de interés comercial, sus características se acomodaban bien a los requerimientos de la minería histórica. De hecho, los orígenes de su explotación son remotos. Las investigaciones arqueológicas, señaladamente los hallazgos del yacimiento de la Orduña, cerca del monasterio de Veruela (Zaragoza), los llevan al siglo IV AC. De ahí en adelante, con un especial florecimiento en torno al cambio de era, del que se hicieron eco los autores clásicos, que encomiaron la excelencia de la metalurgia celtibérica, sobre todo en relación con la producción de armas (Polibio, Diodoro, Filón), y particularmente el de las forjas de las ciudades de Bilbilis - Calatayud- y Turiaso - Tarazona - (Marcial, Plinio), lo que tradicionalmente se ha puesto en relación con la cercanía de los yacimientos férricos del Moncayo (Lorrio, Gómez Ramos, Montero y Rovira, 1999).

Pero tras este brillante arranque, un velo de oscuridad cae sobre estas explotaciones. Abandonadas, o poco menos, en el Bajo Imperio (Blázquez, 1970: 147), apenas hay indicios de su funcionamiento hasta la Edad Moderna. ${ }^{1} \mathrm{Y}$ aunque existe el consenso general de que durante los siglos medievales debieron de tener algún tipo de actividad, la escasez de referencias disponibles y su nula renovación ${ }^{2}$ se han interpretado como sinónimo de irrelevancia, con sus correlatos tópicos: atraso tecnológico, ausencia de inversiones etc. (Benedicto Gimeno y Mateos Royo, 2013: 47 y 185 y ss.). Bien es cierto que esa valoración puede hacerse extensible a, prácticamente, toda la minería medieval aragonesa, que se enfrenta a carencias similares

$1 \mathrm{Y}$ aun para entonces con unos resultados más bien mediocres, según Benedicto Gimeno y Mateos Royo, 2013: 46-48, en un juicio tal vez demasiado severo, al menos para el siglo XVI.

2 Los exiguos datos reunidos hace camino de cincuenta años por Gual Camarena, 1970: 281, no han conocido, en lo referente al Moncayo, ampliaciones significativas en la escasa bibliografía sectorial. 
con muy pocas excepciones; ciñéndonos al sector del hierro, únicamente las explotaciones del valle de Bielsa. ${ }^{3}$

Pero ¿realmente es así o se trata simplemente de una laguna? En este sentido, es muy aleccionador el ejemplo de Castilla donde, hasta hace relativamente poco tiempo, el balance de nuestros conocimientos sobre el tema era, en líneas generales, igual de desolador, tanto en general, como en el ámbito férrico, entorno este último donde, aunque se reconocía un cierto desarrollo - el hierro castellano al fin y al cabo era un artículo de activa exportación ya en el siglo XIII - , territorialmente, el panorama se reducía a una serie de citas dispersas, sin apenas contenido más allá de la simple mención - muy en la línea de lo que hemos visto para el Moncayo-, entre las que únicamente destacaban las manufacturas de Guipúzcoa y Vizcaya (Sánchez Gómez, 1990: especialmente 96 y ss.). Y, sin embargo, en los últimos años se han sido sucediendo aportaciones que han identificado nuevos focos minero-siderúrgicos de más de mediano alcance en otros escenarios de la corona castellana como Cantabria (Solorzano Telechea, 2006; Ceballos Cuerno, 2001; Corbera Millán, 2001), el Bierzo (Balboa de Paz, 1990) o Lugo (González Pérez, 1994), que han demostrado que la cuestión se reducía a una mera falta de estudios específicos.

¿Puede esta circunstancia extrapolarse a nuestra área de estudio? Partiendo de la base de que durante la época medieval el hierro es uno de los minerales más demandados y buscados, solo por detrás de los metales preciosos - el Medievo es una «nueva edad del hierro», como se ha dicho en más de una ocasión-, la hipótesis, de partida, no carece de argumentos. El Moncayo ofrece numerosos pequeños veneros a cielo abierto o a escasa profundidad con una elevada concentración de mena - localizadamente, de hasta el $70 \%{ }^{4}$ - que, dadas las limitaciones técnicas contemporáneas para los grandes movimientos de tierras, son las preferidas por la minería preindustrial (Sánchez Gómez, 1990: 27-29), aparte de abundantes recursos hidráulicos y forestales, las fuentes de energía por excelencia de los establecimientos siderúrgicos coetáneos, las ferrerías en la terminología regional de los siglos tardomedievales y modernos. Por otra parte, hay que

3 Sesma Muñoz, 1995: 229-231, y Ubieto Arteta, 1991: 189. Las minas de hierro y plata de Bielsa son estudiadas, desde sus orígenes medievales hasta su extinción en el siglo XVIII, por Bielza de Ory et alii, 1986: 78-87, aunque para la época moderna sus conclusiones han sido superadas por Pallaruelo Campo, 1994, y Nieto Callén, 1996.

4 Véanse ejemplos de la zona de Ólvega, Beratón y Cuevas de Ágreda en Sanz Pérez et alii, 2001: 41 y 43. 
considerar que en sus cercanías se ubica un gran vía fluvial -el Ebro-, con una larga tradición de tráfico pesado, muy revitalizada a partir del siglo XIII (Sesma Muñoz, 2009), particularmente apropiada para encauzar eventuales excedentes, y diferentes núcleos poblacionales de entidad solamente en el área aragonesa, Tarazona, Borja, Calatayud y, sobre todo, Zaragoza - que garantizan una demanda de metal significativa y estable en el momento en que se consolide mínimamente su despegue urbano, de nuevo en torno al Doscientos.

Ciertamente, hay que contar con la competencia de los muy activos centros de producción vascos y navarros, que está probado que en los últimos siglos del Medievo alimentan, a la par que su proyección atlántica, que es la principal, una activa corriente de exportación férrica hacia el SE, utilizando sobre todo como medio de transporte - precisamente - el Ebro. ${ }^{5}$ Pero aun con todo, la opción del Moncayo resulta atrayente, máxime considerando las tradiciones más o menos nebulosas que subsisten en el territorio acerca de la existencia de viejas ferrerías y la relativa abundancia en el mismo de restos materiales de clara raigambre minero-metalúrgica, si bien hoy por hoy de data indeterminada. ${ }^{6}$ No obstante, es de sobra sabido que la lógica y la historia no siempre marchan de la mano. Por razonable que pueda parecer cualquier supuesto, es preciso dotarlo de contenido. Y ese es, en primera instancia, el objetivo del presente artículo, a través del acopio de noticias documentales publicadas dispersas, algunas bien conocidas, otras no tanto, y de informaciones inéditas procedentes, sobre todo, del Archivo de Protocolos Notariales de Calatayud (APNC), que se ha examinado sistemática-

5 En la segunda mitad del Trescientos las remesas son ya trascendentes, Mugueta Moreno, 2010. Para el siglo XV carecemos de datos cuantitativos acumulados, pero deben seguir siéndolo pues la presencia de mercaderes procedentes de Navarra y del Pirineo occidental es muy significativa en Aragón a mediados de esa centuria; acuden a surtirse, principalmente, de aceite, trayendo de sus lugares de origen, señaladamente, pescado y hierro. Sesma Muñoz, 1982: 73, 79 y 87. En 1423 las ordenanzas de la cofradía de los cuchilleros zaragozanos lamentaban el uso de aceros de mala de calidad, en vez del azero bueno de tallo de Navarra, como antigament solian fazer, Falcón Pérez, 1997: 246-247, doc. 123.

6 No es excesivamente difícil encontrar en la bibliografía local y regional este tipo de alusiones. Así, por ejemplo, Blázquez Herrero y Pallaruelo Campo, 1999: Vol. I, 231, dicen saber de la existencia de fundiciones en Añón, Torre de Ambel, Trahit, Minera Honda, Castillo de Herrera o del Ferrellón, Talamantes, Vozmediano, Agramonte y Trasmoz, aunque sin contar con más autoridad que un artículo periodístico. García Manrique, 1960: 210, habla de restos de antiguas explotaciones en Trasobares, Talamantes, Tabuenca, Ambel, Añón, Trasmoz, Agramonte y de grandes escoriales en el camino que une Añón y Beratón y también en Agramonte, Ambel y Tabuenca, cerca de los pozos de las minas. Chacon, 1989: 832, menciona, dentro de los límites del Parque Natural del Moncayo, a la ferrería de Agramonte y en los montes de Añón, lindantes al mismo, las de Morca y Morana. Etc. 


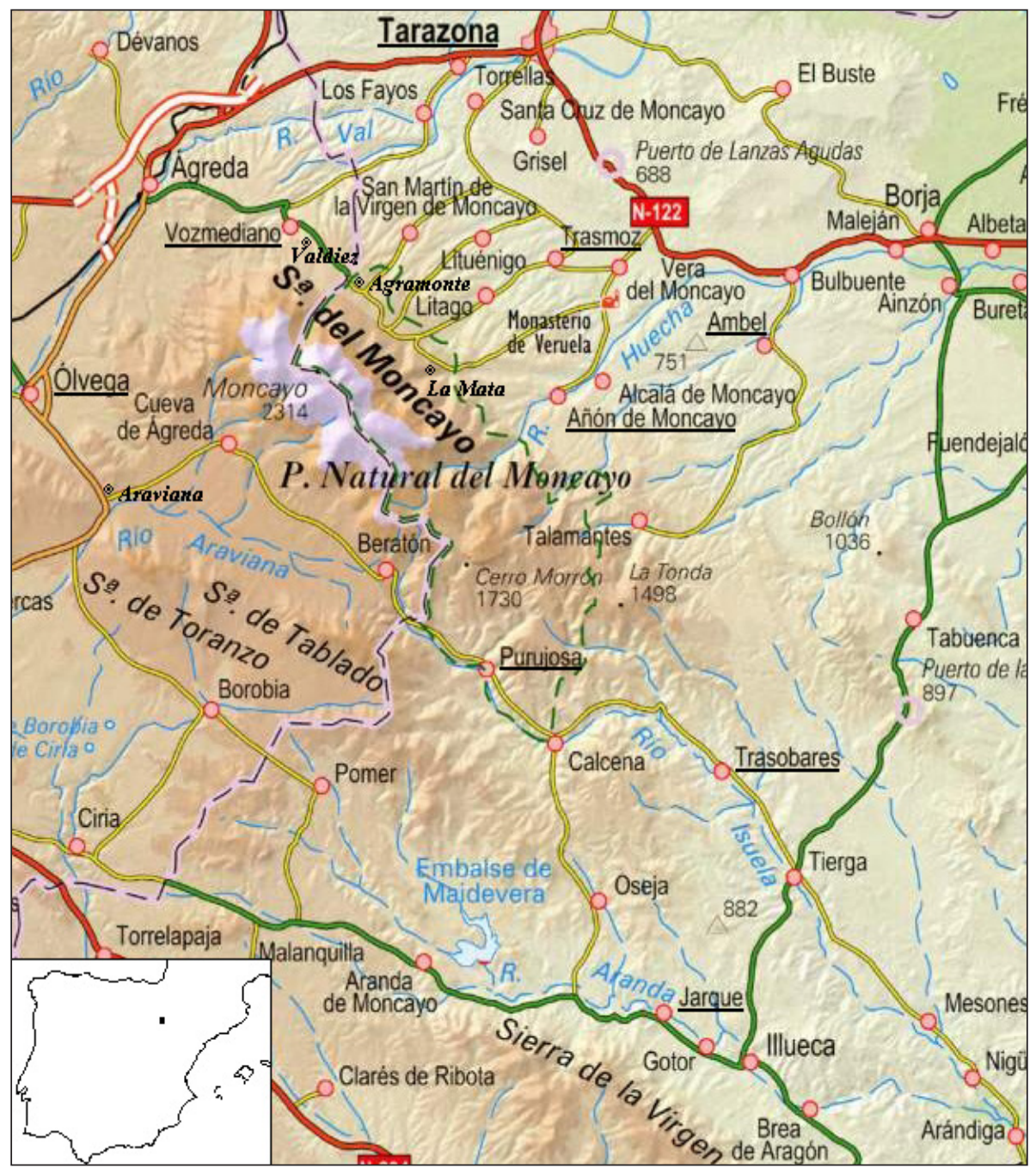

Fig 1. Minas de hierro y ferrerías documentadas en el entorno del Moncayo en la Edad Media Trasobares: municipio contemporáneo en cuyo término se documentan minas y/o ferrerías medievales. Araviana: ferrería localizada con precisión.

mente hasta en torno a la década de 1480 , completadas con algunas referencias puntuales, más fruto de la fortuna que de una revisión metódica, del Archivo de Protocolos Notariales de Zaragoza (APNZ), que sin duda guarda más datos por localizar. El resultado, ordenado por lugares, es el que sigue. 


\section{Minas y ferrerías en el Moncayo y su entorno}

\subsection{Ambel}

Las noticias sobre las instalaciones de Ambel son las más antiguas también de las más conocidas - de todas las documentadas para la zona del Moncayo. En 1245 el justicia de Huesca, siguiendo las instrucciones dictadas por el rey Jaime I y el infante Fernando, su tío, comunicaba a los vecinos de la dependencia templaria de Ambel que estaban exentos del pago de la lezda por razón del hierro y otras mercaderías que llevaban por el reino, salvo en el caso que se tratase de reventas. ${ }^{7}$ En 1247 una sentencia dictada por Vidal de Canellas, obispo de Huesca, volvía a insistir sobre lo propio y en el mismo sentido, aunque de forma más expresiva: ante la pretensión del rey de que los vasallos del Temple habitantes en Ambel debían satisfacer la lezda por el hierro que vendían en Zaragoza y otras villas aragonesas, a lo que se oponían los templarios, el juez falla que, tratándose de metal extraído de sus minas y facturado y transportado por los directos interesados o a sus costas, el gravamen no debía aplicarse, aunque sí en el momento en que entrasen intermediarios en el negocio. ${ }^{8}$

Una primera reflexión. Es obvio que el punto de partida del veredicto es el status jurídico que en estos momentos se aplica a la extracción en la Península y, en general, en toda Europa: un derecho comunal, como los pastos o las leñas, al alcance formalmente de todo habitante en el lugar. El laudo del obispo de Huesca lo único que hace, en este sentido, es extender esa libre facultad a la comercialización, con el único requisito de que se trate efectivamente de un ejercicio de los titulares positivos del derecho: los vecinos de Ambel. Pero esta concepción está evolucionando lentamente. A partir del siglo XII, si bien de una forma irregular y plagada de obstáculos, las monarquías hispanas, como las del resto del continente, empiezan a reclamar el subsuelo como un atributo inherente a su autoridad - esto es, como una regalía - , una batalla en la que

Archivo de la Corona de Aragón (ACA), Pergaminos, Jaime I, Serie general, 1.011. El diploma copia el tenor documental de la carta remitida por el rey, texto este último que fue publicado por Huici Miranda y Cabanes Pecourt, 1976: Vol. I, 200, doc. 410.

8 ACA, Pergaminos, Jaime I, Serie general, 1.076. Publica el documento por primera vez Arco, 1916 : 515-516, doc. VII. Este autor data el texto el 12 de marzo de 1246. Sin embargo, los inventarios del archivo de custodia lo adjudican al mismo día de 1247, como puede verificarse en el Portal de Archivos Españoles (PARES), http://pares.mcu.es/ (fecha de consulta: 30/05/2015). Esta última cronología es la comúnmente aceptada. No habiendo tenido oportunidad de consultar el original es la que sigo. 
consumirán siglos y que tropezará, entre otras resistencias, con las de los concejos, que no se resignaran dócilmente a la pérdida de sus viejos derechos consuetudinarios, aunque bien es cierto que atendiendo a sus propias aspiraciones: convertirlos en lo que en época moderna se llamarán bienes de propios (Sánchez Gómez, 1990: 78 y ss.; para Aragón, específicamente, Benedicto Gimeno y Mateos Royo, 2013: 136-139).

En segundo lugar, advirtamos que el conflicto, a juzgar por el rango de sus intervinientes, no es menor. La autoridad regia por un lado, la poderosa orden del Temple por otro y Vidal de Canellas, el jurista más influyente del reino, futuro compilador de los Fueros de Aragón — recibe el encargo ese mismo año de 1247 - , como juez mediador. Con estos antecedentes resulta razonable suponer que el caso remite a una producción férrica que debe tener, para los parámetros de su tiempo, su aliciente, aunque hay que convenir que, tratándose de una materia prima como esta, de alto valor estratégico en cuanto fundamento de la fabricación de armas, pueden existir factores distorsionadores. En cualquier caso, el mero hecho de que la colocación de sus excedentes suponga trascender la esfera espacial más inmediata y entrar en los circuitos comerciales regionales - Zaragoza vel ad alias villas regis - es ya es un factor a tener en consideración.

La pregunta inmediata es ¿con qué medios tecnológicos cuentan los de Ambel para alcanzar esos resultados? Desgraciadamente, el fallo es, a priori, absolutamente opaco en este sentido. En ningún momento evoca, ciñéndonos a la terminología más corriente en la comarca hacia la fecha,fabricas, forgas, fargas, ferrerias o similares, sino, simplemente las labores de extracción, sin entrar en detalles de ningún tipo de cómo se transforma el mineral y con un fuerte acento en que se trata de un quehacer poco menos que individual, eso sí, abierto potencialmente a todo el mundo, con el único requisito del arraigo en la villa. Como dice muy gráficamente el documento, el metal que obtiene cada uno de los habitantes de Ambel con sus propias manos o a sus expensas de su excavación particular - sua propria ferri fodina-. Resulta sin duda arriesgado intentar llegar a conclusiones en el ámbito técnico a partir de un texto de una naturaleza y unos intereses totalmente diferentes. Pero, a pesar de todo, resulta extraño que, de existir alguna traza de instalación desarrollada, aunque fuese embrionariamente, el obispo no le hubiese hecho algún guiño.

Caben interpretaciones, por supuesto, pero da toda la impresión de que nos encontramos, no ante un taller o talleres al uso, sino ante lo que hoy llamaría- 
mos una industria tradicional ejercida de forma difusa por el vecindario utilizando infraestructuras necesariamente sencillas, aunque sin perder de vista las actividades agrarias convencionales, que tienen en estos momentos $-\mathrm{y}$ seguirán teniendo - un peso fundamental en la economía de Ambel (Gerrard, 2003: especialmente 83-95). No es algo inédito en las serranías medievales ibéricas. En Sierra Menera, el otro gran foco histórico minero-metalúrgico de la cordillera, la arqueología ha identificado una serie de pequeños asentamientos andalusíes con una cronología muy concreta, segunda mitad del siglo XI, los cuales, prácticamente en su totalidad, combinaban la agricultura y la ganadería con la extracción y siderurgia férricas, con conexiones incluso con los mercados urbanos (Ortega Ortega, 2008). Lo más interesante es que, tras el paso definitivo de la comarca a control cristiano en la segunda mitad del siglo XII, con las novedades de rigor en el orden social y la red y ordenación del poblamiento, esta estrategia productiva diversificada - labores metálicas incluidas - se reprodujo haciéndose, incluso, más heterogénea y perviviendo, como mínimo, hasta el siglo XIV (Iranzo Muñío y Ortega Ortega, 2011: 88-116).

Es, pues, perfectamente posible que las labores metálicas de Ambel, como las de Sierra Menera, sean como nos las representa tácitamente el documento: poco singularizadas, desde el punto de vista comunitario, y relativamente elementales, desde el tecnológico. Si trasponemos estos condicionantes al solar de la técnica siderúrgica no cabe más que un candidato: los hornos de reducción directa, una tecnología heredada de la Antigüedad - de hecho es la base de la metalurgia celtibérica-, en estos momentos en trance de ser superada por las nuevas ferrerías hidráulicas, pero que a mediados del Doscientos sigue teniendo un protagonismo indiscutible al sur de los Pirineos. ${ }^{9}$ Es muy simple en sus requerimientos materiales, pues no consiste más que en un horno bajo, parcialmente excavado en la tierra, cerrado con piedras y dotado con un pozo de salida de escorias y las correspondientes entradas de aire. Sin más. Sus ventajas son su fácil construcción, mínimo coste y pocas exigencias específicas. Sus inconvenientes, que supone una fuerte carga de duro trabajo humano, pues la separación de las escorias y la compactación de la masa férrica tras la reducción debe realizarse martilleando a mano - la labor que heredará el mazo hidráulico en el fase tecnológica superior - y que su capacidad productiva unitaria, a juzgar por los ejemplares conocidos, es habitualmente corta, 
aunque nada impide multiplicar los dispositivos, que es sin duda la fórmula seguida para el incremento de remanentes cuando así se estima necesario.

Los trabajos férricos en Ambel debieron tener algún tipo de continuidad, al menos en el segmento de la extracción, pero de un perfil más bien bajo, pues no hallo mención alguna posterior salvo una muy tardía. A principios del siglo XVII, un pleito sobre derechos mineros - en el contexto de esa oposición a las pretensiones de la Corona sobre la materia de la que hablábamos más arribasaca a colación una serie de municipios aragoneses, entre ellos Ambel y otros concejos de la comarca - Añón y Trasmoz-, que se aprovechaban de las vetas férricas de su término sin dar cuentas a la hacienda real, pretextando derechos inmemoriales (Benedicto Gimeno y Mateos Royo, 2013: 219). Sobre el terreno, es posible identificar dos áreas mineras pretéritas en este municipio, junto a la Torre de Ambel y al E de la Paridera del Alto (Gerrard, 2003: 97).

\subsection{Jarque}

Ya en 1264 Jaime I concede a Blasco de la Navarra autorización para extraer de las meneras del término de Jarque, villa de realengo, ${ }^{10}$ hierro, acero y cobre y para edificar y poseer las forgas, fornaces o frabegas para ello necesarias, pagando por cada mafuga $a^{11}$ de hierro 4 dineros (ds.), el quinto del cobre obtenido y una séptima parte del acero. ${ }^{12}$

Es una noticia muy sugestiva. Para empezar, nótese que no se trata de una licencia de mera prospección, sino de una empresa que tiene unos propósitos definidos, en cuanto se ciñe a unos metales muy concretos, y que, por tanto, parece pisar terreno firme. Es, por otra parte, ajena a los derechos vecinales ge-

10 Aunque por poco tiempo: en la década de 1270 entra en la órbita señorial para no salir, cf. García Marco y Motis Dolader, 2001: 76 y 82.

11 No he conseguido identificar propiamente este término. Pienso que, posiblemente, sea una variante o incluso una mala transcripción de samuga, cuyo uso sí se documenta en el Aragón bajomedieval, Sesma Muñoz y Líbano Zumalacárregui, 1982: 319. Según la RAE, y con ella todos los diccionarios, glosarios y vocabularios que he consultado, la samuga (o jamuga) es la estructura de madera, a modo de silla de tijera, que se coloca sobre el aparejo de las caballerías para montar a mujeriegas. Pero encuentro que en el Aragón tradicional ese avío es también utilizado para colocar bultos en los lomos de una acémila, como por ejemplo — no creo que sea casual - cuando se transporta por el monte carbón vegetal, desde la carbonera, en plena floresta, hasta poblado: dos sacas por animal, colocadas de pie, una a cada lado de su lomo, Monesma Moliner, 1993: 73. Desde este punto de vista, mafuga podría equivaler a «carga de una caballería».

12 ACA, Cancillería, Reg. 13, f. 170v. El texto es consultable de forma directa a través de PARES (véase la dirección supra). Me facilita la referencia Palacios Martín, 1977: 285, en nota. 
néricos, personalizándose en un individuo que, en reconocimiento de la potestad del soberano, se compromete a satisfacerle la cuota que éste le designa. Sugiere, evidentemente, un proyecto de nuevo cuño pero, sobre todo, de cierta ambición. Esta mayor altura de miras va en consonancia con la presunta categoría de las instalaciones que se prevén fundar, que tienen el suficiente empaque como para que su propiedad sea expresamente asegurada al interesado en la concesión. El detalle no es baladí, pues no hay que olvidar que los hornos de reducción férrica directa típicos, no es que no fueran permanentes, es que ni siquiera tenían una ubicación fija; levantados cerca de las reservas de mineral o de madera, se trasladaban en el momento en que éstas empezaban a flaquear. ${ }^{13}$

Por otra parte ¿quién es Blasco de la Navarra? No, desde luego, ningún personaje prominente ni socialmente relevante pues, aparte de que no lo consigo documentar por ninguna parte, en el texto no recibe ningún tratamiento, tan solo la calificación de habitatori - ni siquiera vecino-de Xiarch, localidad por otra parte con una importante población mudejar. Así las cosas, cabría especular con la posibilidad de que se tratase de un plebeyo emprendedor, incluso quizás perito en el oficio, a juzgar por la procedencia que denota su apellido: la zona vasconavarra, patria natal de la inmensa mayoría de los ferrones que trabajaron en el Aragón medieval y moderno.

Finalmente, cabe considerar las denominaciones aplicadas a las instalaciones: fornaces seu forgas y, en otra mención, frabegas seu fornaces. El apelativo más repetido, fornaces, no tuvo mucha fortuna en la región. Únicamente, lo hallo en Aragón, a principios del Trescientos, en el Pirineo, en Bielsa, aunque no en conexión con el hierro sino con el refinado de plata (Bielza de Ory et alii, 1986: 186-189). Con el hierro sí aparece relacionado en - justamente - Navarra en donde, para esos mismos años, las primeras alusiones documentales de ingenios siderúrgicos rastreadas en ese reino los nombran como fuegos o fornesiis, relacionándolos además - como en Bielsa - con el uso de la fuerza hidráulica (Mugueta Moreno, 2009: 15-16). El término fue pronto eclipsado, tanto en Aragón como en Navarra, por el de ferreria, que se convirtió en el de uso más habitual en la Baja Edad Media y después.

Nada sabemos de la eventual plasmación de la regia concesión de Jarque, pues no hay nuevas sobre la materia en este lugar hasta más de dos siglos después. El 12 de abril de 1488 Lope Ximénez de Urrea, flamante conde de Aran-

13 Las prospecciones arqueológicas de los vestigios mineros andalusíes de Sierra Menera ofrecen buenos ejemplos de lo que su responsable llama una «metalurgia nómada», Ortega Ortega, 2008: 118-119. 
$\mathrm{da}^{14}$ - señorío en el que, con el tiempo, ha pasado a integrarse Jarque-, acuerda con el ferrero vizcaino Julián Navarro un articulado para la construcción de una ferrería en la villa y la búsqueda de hierro en sus estados. ${ }^{15}$ Las pesquisas deben ser fructíferas pues, muy poco tiempo después, el 21 de junio de aquel mismo año, ambas partes replantean el negocio y pactan una nueva capitulación que, presuntamente, sustituye a la primitiva. ${ }^{16}$ Temática y tipológicamente, son dos documentos excepcionales, sin análogos en toda la historia de la minería medieval del hierro, tanto de la cordillera Ibérica como del reino de Aragón, y que, por tanto, merecen un examen detenido. Las cuestiones atendidas son:

Las condiciones de la prospección y la apertura de la mina, que son totalmente a cargo y despesa del vizcaíno hasta el momento de acceder al filón. En el primer concierto se prevé que, en correspondencia por estos trabajos, el señor de Jarque condonará 25 florines del monto del arrendamiento del ingenio, la añada que él decida. Pero esta estipulación desaparece en el definitivo.

La obra del instrumental y del local que ha de servir de ferrería y de vivienda para sus laborantes, expedientes que si en la primera capitulación, se adjudican a la cuenta del conde de Aranda por entero, sin entrar en excesivas precisiones, en la segunda, se comparten entre los dos contratantes conforme a un programa detallado. El técnico, a sus costas, alzará el edificio convenientemente - los cimientos, de dos palmos de profundidad, con argamasa, el alzado, de buena tapia, y la cubierta, de madera - y proporcionará el equipo: barquinos, çobra, machos, tenacas y otros qualesquiere pertrechos y ferramienta para la dicha ferreria nescessarios. En compensación, el propietario le concede, a los efectos, una ayuda de 2.000 sueldos jaqueses (ss. j.) y 130

14 El diploma de concesión del título se expidió el 8 de enero de 1488.

15 Técnicamente, por tanto, la mina no tiene porqué estar necesariamente en Jarque. Otras localidades de los contornos que forman parte del señorío son Aranda de Moncayo, Tierga y Mesones de Isuela, véase Navarro Espinach, 2009. En Tierga subsiste el único yacimiento hoy en activo de toda la sierra: la mina de Santa Rosa que, a partir de una veta de hematíes de gran pureza y alto contenido férrico, produce ocres industriales. En Mesones, por su parte, se observaban a fines del siglo XVIII perforaciones profundas abandonadas relacionadas con la búsqueda de minerales, Monterde y López de Ansó, M., 1798: 97.

16 Transcribo ambas en el Apéndice documental, aparte de por su interés y rareza, por previsión: el estado de conservación de los originales no es el más deseable. La existencia de estos documentos ha sido anotada por diferentes investigadores, aunque solamente les ha dedicado, hasta hoy, un comentario mínimamente detallado Pérez Viñuales, 1996: 540-541. Es testigo de los dos contratos Ferrando de Montesa, mercader, ciudadano de Zaragoza, que, por otro documento, sabemos que es, o ha sido hasta fecha reciente, procurador de Lope Ximénez de Urrea, véase nota 43. 
peonadas y la patente para cortar gratuitamente toda la madera que necesite en los lugares de Aranda, Jarque, Mesones y Tierga y también - concretamente, para las ruedas - en la partida de La Mata, término de Trasmoz, todos ellos dependientes de la jurisdicción condal. Pero solamente en los montes, excluyendo expresamente la guerta de dichos lugares, de donde, si algún tronco precisa, deberá pagarlo a su dueño. De los gastos del transporte, tanto de dicha madera como del utillaje, se hace cargo el de Urrea.

Los términos de la cesión del usufructo: el primer ajuste establece que, en el momento que la ferrería esté operativa, el señor la arrendará al ferrón durante seis años pagando éste tres quintales (qs.) semanales de metal — unos 150 al año-, fórmula sustituida en la segunda concordia por un periodo de carencia de dos años, durante los cuales Julián Navarro se lucrará de la producción sin deducción alguna; al finiquitar dicho plazo, el vizcaíno deberá dejar la ferrería en estado operativo - molient y corrient - con todos sus utensilios, sinse empacho alguno.

La infraestructura precisa para el suministro hidráulico, que corre por cuenta del de Urrea, el cual se compromete a sufragar la realización de una acequia y azud para que benga el agua a la dicha ferreria y pueda moler y andar aquella devidamente.

La provisión de carbón: mientras Navarro esté a cargo del establecimiento, puede cubrir este capítulo de sus necesidades utilizando libremente los montes del principal. Realmente la estipulación solamente se contempla en la primera composición, ignorándose en la segunda, pero debió mantener su vigencia pues no cabe otra opción.

Particularmente interesante desde el punto de vista tecnológico es la alusión a los barquinos, nombre dado - sobre todo en el área vasconavarra, de donde procede Julián Navarro- a los fuelles mecánicos accionados por energía hidráulica utilizados para forzar la alimentación de aire del horno, que son el aporte primordial de la aplicación de la fuerza del agua a la historia de la siderurgia, por encima del martillo hidráulico (Verna, 2011: 631 especialmente). Permitían ganar temperatura, lo que redundaba en una notoria mejora de la productividad y la calidad del metal, si bien al coste de incrementar considerablemente el consumo de combustible. Aunque, a finales del Cuatrocientos, distan mucho de ser ninguna novedad — en la Península aparecen sobre el 1300 en Cataluña (Sancho i Planas, 2011: 662) y en la segunda mitad del siglo XIV en Navarra y Guipúzcoa (Mugueta Moreno, 
2009: 20-22) - , es la alusión más antigua que he podido rastrear de este tipo de artefactos en Aragón y en el sistema Ibérico asociados a la fundición, ${ }^{17}$ los cuales, por otra parte, aseguran a la factoría de Jarque unos rendimientos potenciales muy apreciables.

El aristócrata cumplió su parte del trato: el 23 de agosto de aquel ejercicio el ferrero le extendía un albarán por los 2.000 ss. j. que de él había percibido para ayuda de las ferrerias y cosas de aquella que yo tengo de hazer en Exarque ${ }^{18}$ también Julián Navarro, que levantó la fundición y todavía en 1494 permanecía a su frente: el 28 de enero de esa añada figura como testigo de cierta carta redactada en Calatayud con la calificación de habitante en las ferrerias de Jarque ${ }^{19}$ (cit. García Marco, 1993: 180, en nota). En este punto se interrumpe nuestra información.

\subsection{Añón}

La industria de Añón debió nacer en 1279 o poco antes. El 12 de septiembre de aquel ejercicio el rey Pedro II escribe a Muça Portella, uno de sus bailes, para que vede el trabajo y secuestre las minas y ferrerías - frabicis seu ferrariis - que los hospitalarios y, señaladamente, fray Bernardo de Crebaño, al que se presenta como responsable principal de la iniciativa, ${ }^{20}$ han abierto en

17 Esto no quiere decir que, para estas fechas, el término barquino sea desconocido en el reino aragonés. Todo lo contrario. En el ámbito de la herrería, se documenta sin excesivas dificultades desde la segunda mitad del siglo XIV. El inventario de una fragua zaragozana elaborado en 1374 registra ya unos barguinos (Falcón Pérez, 1996: 371), por ejemplo. Pero se trata de fuelles manuales, no hidráulicos, de corta potencia. En 1464 el concejo de Ateca, una población de los alrededores de Calatayud, decide renovar, a costa de la corporación, el equipamiento de la herrería local, lo que supone la adquisición, entre otros útiles, de unos barquinos que cuestan 56 ss. j. (Rubio Semper, 2006: 294, entrada 3737), una suma módica para un instrumento de este tipo, que habla con claridad de que se trata de un ejemplar de tamaño relativamente pequeño, del tipo antes aludido. No es el caso del previsto para Jarque, donde su enlazamiento con la utilización de la potencia hidráulica permite asegurar que se trata de un modelo mecánico.

18 APNZ, Antón de Abiego, notario de Épila, 1488, cuadernillo 9, f. 55v.

19 Una pequeña nota metodológica: con el nombre de ferrerias se designan en la época tanto a las simples herrerías como a los auténticos centros metalúrgicos. No siempre es fácil distinguirlos. Una de las formas posibles es el contraste de su ubicación. Mientras las primeras suelen integrarse en el caserío de la comunidad a la que dan servicio o en sus inmediaciones, los segundos, lo más común es que se encuentren en despoblado, cerca de las bocas de las minas o de los bosques que los proveen pero, sobre todo, de los cursos fluviales, de los que dependen para el movimiento de su maquinaria. En este sentido, el que unos individuos habiten en una ferrería en vez de en una villa, aldea o lugar denota bastante claramente que nos encontramos ante un taller siderúrgico.

20 Se trata de un personaje de cierto relieve, que ha colaborado ocasionalmente con la administración regia y es calificado en algunos documentos de comendador de Mallén, Romano, 1983: 62. 
Añón, lugar vasallo de la orden, y que carecen por completo de precedentes: de novo fecerunt. El soberano justifica la medida arguyendo la regalía de la corona sobre cualquier extracción metálica en una contundente declaración de principios: omnes mene [s] cuiscumque matalli (sic.) sunt que, in nostra terra seu iurisdictione inventione fuerint, ad nos dinoscantur pertinere.

Pero los hospitalarios no cooperan. El 9 de abril del año siguiente Pedro II vuelve a dirigirse a su servidor para que reitere al comendador de Añón la prohibición de operar y le compela a ello por los medios que sean necesarios, incluida la pignoración, pues estima - muy significativamente - que la actividad de las ferrariis sive menis de Anyon... est periudicium nostrum. El 27 de julio el conflicto ha alcanzado grandes proporciones: el propio castellán de Amposta, prior de los hospitalarios en los territorios de la Corona de Aragón, se queja al rey de la conducta de Portella a causa de la empara de la forgia de Anyo[n], un asunto lo suficientemente grave como para que el soberano solicite el dictamen de sus consejeros. ${ }^{21}$ No sabemos cómo concluyó la cuestión, aunque es sorprendente el grado de tensión alcanzado. La reivindicación regia sobre las minas se centra en la Edad Media, eminentemente, sobre las salinas y las argentíferas, en este último caso en cuanto relacionadas con otra de las grandes regalías del trono, la acuñación de moneda. Para las demás, y especialmente las de hierro - las más numerosas - , en la práctica, es mucho más laxa, por múltiples razones: la baja rentabilidad de muchas de ellas, la prevalencia de costumbres locales preexistentes, la falta de normativa desarrollada, las protestas de los propietarios mejor situados - nobles y ciudades - , que a veces degeneran en auténticas revueltas ${ }^{22} \ldots$ Casi siempre debe conformarse, en el mejor de los casos, con un reconocimiento puramente simbólico, sustanciado en una mera participación la producción, vía fiscal (Sánchez Gómez, 1990: 90), como hemos visto para Jarque. El encono del rey en dejar en suspenso la explotación de Añón es innegablemente singular. Pero dejemos, de momento, la cuestión abierta. La retomaremos en el epígrafe dedicado a Trasobares.

21 ACA, Cancillería, Reg. 42, ff. 139v-2 y 246v-4 y Reg. 48, f. 62-2, respectivamente. Estos instrumentos pueden visualizarse en línea a través de PARES (véase la dirección supra). Tomo estas referencias de Romano, 1983: 37 y 40.

22 Según Gual Camarena, 1970: 279, la posesión de las minas de Vizcaya fue uno de los motivos de la sublevación de los nobles castellanos en 1273 contra Alfonso X, al que reclamaban que el ferro torne a aquel estado que solia en tiempo de su padre. El rey Sabio había formulado en términos muy taxativos la regalía minera en las Partidas. 
En la segunda mitad del Cuatrocientos seguía en funcionamiento en la localidad un complejo. El 20 de septiembre de 1460, en Calatayud, Joan d’Udala y Rodrigo Saldiva, vizcainos, habitantes en las ferrerias del lugar de Anyon, tomaban sendas comandas de Martín de Castro, ferrero, vecino de dicha ciudad, por 9 y 25 florines respectivamente, cuya devolución garantizaban, el primero sobre dos mulos y el segundo sobre otro mulo y unas casas suyas sitias en el dito luguar, que afruentan con las dichas ferrerias et con la carre$\mathrm{ra}^{23}$ Considerando la índole de los implicados, seguramente se trataría una venta de hierro encubierta, como se decía por aquel entonces, a dineros anticipados.

No mucho después, el 9 de enero de 1469, Sebastián de Sarría, alcaide del lugar de Añón, vendía a Pedro de Montesa, notario, ciudadano de Calatayud, 250 qs. de hierro, fecho de la mina del dicho lugar de Anyon, a 18 ss. j. la unidad, puestos en las casas del comprador en Calatayud, en el plazo de un año, a contar del próximo 1 de febrero, a razón de 21 qs. al mes, poco mas $o$ menos, bien entendido que el pago había de hacerse en moneda de oro - bien anriques, contando a 26 ss. j. cada uno, bien florines, a 14 ss. j. - y que el vendedor se comprometía a no despachar, ni directa ni indirectamente, más hierro a la ciudat de Calatayut, a los lugares de Villafelix, Mores ${ }^{24}$ ni a las aldeas et territorio de la dicha ciudat de Calatayut durante el tiempo de vigencia del contrato, de donde cabe deducir que el vendedor cuenta, en potencia o en acto, con stocks suplementarios. Cabe subrayar que Sarría no es ningún ferrón sino una autoridad local, que debe actuar en nombre de la señoría, aunque lo cierto es que tal circunstancia no queda expresa en ningún momento. Desgraciadamente no sabemos en concepto de qué el objeto de la venta llega a sus manos. Lo más lógico es que se trate del fruto del arrendamiento de las ferrerías, que cobra por delegación - lo que, dicho sea de paso, implicaría una productividad total notable-, pero también puede obedecer a otras causas; algún tipo de adelanto de fondos a los operarios, amortizable en especie, por ejemplo, un tipo de operación muy reiterada en el contexto.

23 APNC, N. ${ }^{\circ} 26$, Jaime García, 1460, f. 472r-v.

24 Se trata de dos poblaciones de señorío cercanas a Calatayud. Resulta interesante que el documento las individualice expresamente, sin duda en atención a su especial protagonismo en los trabajos locales del metal. Cabe destacar que ambas poblaciones están habitadas mayoritariamente por mudéjares, una minoría con una fuerte inclinación por estas actividades. De hecho, Villafeliche, que cuenta con la morería cuantitativamente más importante de los contornos -197 unidades fiscales en el fogaje de 1495 - , tiene un barrio o arrabal denominado de las Herrerías habitado fundamentalmente por mudéjares, García Marco, 1993: 119, 155 y 180 y ss. 
Al poco tiempo, el 8 de noviembre de 1471, de nuevo en Calatayud, Sebastián de Sarria volvía a convenir un trato parecido, aunque esta vez sin condiciones específicas, con García de Maluenda, cambiador, también ciudadano de la urbe del Jalón, por 200 qs., al mismo precio que anteriormente -18 ss. j./q. - e igualmente comprendidos los portes hasta Calatayud, a entregar en tandas mensuales de, aproximadamente, 18 qs. hasta el día de S. Miguel de septiembre siguiente. ${ }^{25}$

Pero la producción de Añón no solamente surtía los somontanos ibéricos, también llegaba a Zaragoza. En febrero de 1492 las ferrerías de Añón y Vozmediano - un taller castellano del que nos ocuparemos más adelante- se comprometían a entregar en la capital aragonesa 32 qs. de hierro ese mismo mes $\mathrm{y}$, desde marzo a agosto, 15 qs. suplementarios mensuales por un precio total de 2.064 ss. j., es decir, a unos 17 ss. j. la unidad (Sesma Muñoz, coord., 1992: 188, sin referencia documental).

Hay testimonios posteriores de actividad siderúrgica escalonados a lo largo de toda la Edad Moderna, aunque ya no fundiendo mineral local sino de otras procedencias comarcanas. Permiten asegurar que en Añón perduraron estas labores hasta principios del Ochocientos en lo que podría ser el caso más longevo de todo el entorno. ${ }^{26}$

\subsection{Trasobares}

Los primeros talleres de Trasobares son contemporáneos a los de Añón. El 13 de mayo de 1280 Pedro II el monarca escribe a la abadesa del convento de Trasobares protestando por los impedimentos que está interponiendo a los hombres designados por su baile, el ya citado Muça Portella, para trabajar in menis nostris ferrii sive fabricis y rogándole afablemente que deponga su actitud. El recado no hace mella en la religiosa, que persevera, dando pie a que el rey, a instancias de Portella - que tiene la forja bajo su responsabilidad di-

25 APNC, N. ${ }^{\circ} 47$, Leonart de Santa Fe, 1471, ff. 405v-406r.

26 En 1518 la ferrería estaba arrendada al mercader zaragozano Cristóbal Morales, según veremos más adelante en el apartado dedicado a Trasmoz. Referencias de mediados del siglo XVI en Blázquez Herrero y Pallaruelo Campo, 1999: Vol. I, 231-232. Para principios del Seiscientos, vid. Labaña, 1895: 122. Datos de los siglos XVII y XVIII en Benedicto Gimeno y Mateos Royo, 2013: 47-48 y 219. Etc. Todavía funcionaba en los estertores del Setecientos, Asso, 1798: 213. Pero a mediados del siglo XIX Madoz, en su Diccionario, ya no evoca más que sus ruinas en medio del bosque, lo mismo que el botánico Alejandro Jubera, cit. Sanz, 1935: 32. 
recta $^{27}$-, le remita una nueva carta el 12 de julio de aquel mismo año ordenándole, ya sin contemplaciones, que deje operar sin obstáculos a los obreros de las ferrerias de Tresovares. La situación no se prolongó, sin embargo, mucho tiempo renunciando la corona a los pocos años a la gestión de la forja, la cual en 1283 había sido vendida al judío Jucef Xarquí, al parecer habitante del reino de Valencia. ${ }^{28}$

Este dato es excepcional: una cosa es la reivindicación de la propiedad minera por la testa coronada y otra, totalmente distinta, su implicación directa en la explotación, algo que, para estas fechas, aunque sea de forma temporal, es extraordinariamente raro, ${ }^{29}$ máxime tratándose de un yacimiento de un mineral relativamente común, como es el hierro, situado, a mayor abundamiento, fuera del realengo. Es posible así entender muchas cosas. En primer lugar, la hostilidad de la priora. Trasobares fue entregada en 1188 a Toda Ramírez para que fundase el cenobio femenino al que la villa prestó el nombre y, desde entonces, la población permaneció en poder del convento a todos los efectos - excluida la jurisdicción criminal - hasta que a principios del Cuatrocientos el Papa Benedicto XIII aplicó sus rentas a la Cámara Apostólica (García Marco y Motis Dolader, 2001: 74). El que el rey interfiera en el señorío, aunque sea arropado en el ejercicio de su regalía, no puede ser entendido más que como una intromisión inaceptable. En segundo lugar, el empecinamiento de Pedro II en el cierre de la ferrería de Añón, que no es sino una instrumentalización de sus pretensiones sobre el dominio indiscriminado del subsuelo para la eliminación de lo que parece un competidor molesto - recordemos: la forja de Añón «le perjudicaba» - , con la vista puesta en la consecución de esa meta tan cara a la época como es el monopolio de un abasto, en este caso el hierro local.

No encuentro más información posterior para este municipio, al menos en relación con el hierro, ${ }^{30}$ a pesar de que el monasterio, ya en época moderna,

27 En cierta carta que dirige el rey a la abadesa en relación con otro asunto - la provisión de la alcaidía de Trasobares - , vuelve a salir a colación Muça Portella con el título de baiulo domini regis in ferrariam de Treso[v]ares, ACA, Cancillería, Reg. 60, f. 75r-2. Todas las referencias documentales que manejo para Trasobares me las brinda Romano, 1983: 41 y 51.

28 La procedencia de estas informaciones son, respectivamente: ACA, Cancillería, Reg. 48, ff. 20-4 y 79-4 y Reg. 61, f. 155v-5. Véase nota anterior.

29 De hecho, para el Doscientos, sólo conozco otro caso en el solar hispano: el de las minas de Almadén. Véase Sánchez Gómez, 1990: 99 y ss.

30 A principios del siglo XVII Ximénez de Aragués, 1630: 98, menciona minas de plata en Trasobares, con las que acaso haya que relacionar a dos técnicos alemanes avecinados en la población a mediados del Quinientos, véase nota 37. 
mostró episódicamente interés por el sector: en 1672 obtenía licencia del Consejo de Aragón para abrir minas férricas en Calcena y Talamantes, siempre que no causaran perjuicios a las existentes, y erigir nuevas fábricas de fundición (Benedicto Gimeno y Mateos Royo, 2013: 48).

\subsection{Purujosa}

No me consta la apertura de minas en la Edad Media en este lugar, pero sí la de una ferrería en marcha en el último tercio del siglo XV. Ya el 1 de julio de 1467, en Calatayud, Joan de Olave, vizcaíno, habitante de las ferrerías de Purujosa, y Yahie el Ferrero, moro de Gotor, toman en comanda de Jaime Corriz, mercader, ciudadano de Calatayud, $400 \mathrm{ss}$. j. avalados sobre dos mulos propiedad del primero y una viña del musulmán. ${ }^{31}$

El 4 de septiembre de 1483, de nuevo en Calatayud, Joan de Arturiaga y Machín de Reder, igualmente vizcaínos y habitantes en la ferrería de Purujosa, juran dar a Beltrán de Lizana, escudero habitante de dicha ciudad, de tres en tres meses vinte et cinqo quintales de buen fierro mercadero etc., contaderos los tres meses del dia present en adelant, fasta seyer pagados justa la composicion entre ellos firmada, la qual fue firmada mediant notario en el lugar de Aninyon. ${ }^{32}$ Uno de los testigos del acto es otro vizcaíno, maestre Pascual de Carpio, ferrero bilbilitano, que es avalista de Machín de Otalora, también reconocido como vizcaíno, en el arrendamiento de la farga de Purujosa a su dueña, la muy noble señora Dianira de Luna y de Lanuza. El contrato no debía marchar demasiado satisfactoriamente pues, pocos meses después, el 23 de febrero de 1484, ante la cercanía de su desenlace previsto para el día de Navidad siguiente - , Carpio tiene que asumir documentalmente, en su condición de fiança e plano pagador, la responsabilidad de dexar, passado el dicho tiempo..., las dichas ferrerias andantes y corrientes, mejoradas y no enpeoradas, so pena de perjurio y la garantía de todos sus bienes, especialmente la casa donde reside en Calatayud. ${ }^{33}$ La relación de Pascual de Carpio con este taller debía ser en estos momentos tan intensa como fluida, pues el 31 de julio de aquel mismo año Pascual Yáñez, vecino de Aranda - otro pueblo de los contornos - , le nombra procurador para cobrar los 110 ss. j. que le debe Machín de Arradia, un vizcaíno más 
radicado en la forja — tal vez el mismo Machín de Reder, nombrado más arriba-, mediante juramento. ${ }^{34}$

Machín de Otalora, como se anunciaba, no renovó el tenencia de la ferrería, que en 1488 detenta otro norteño, Joan de Ubide, el cual, presentándose como arrendador de la misma y vecino de Purujosa, nombra procuradores el 4 de julio de aquel ejercicio, una vez más en Calatayud, a sus moços Pedro de Oquendo, Machín de Liçauru, Sancho Miguel y Pedro Ibáñez, para presentar el privilegio de la franqueza que ha et tiene de la baronia de Illuequa, a qualesquiere letzeros, peatgeros e pontageros. ${ }^{35}$

No he hallado evidencias de que en los siglos modernos subsistieran en Purujosa estas actividades. Como contrapartida, se documenta una iniciativa de carácter extractivo en 1568, en que el conde de Morata - titular desde 1564 de una extensa concesión minera en el Moncayo - financia la construcción de una casa en el término para los mineros alemanes a su servicio (Acerete Tejero, 2001: 18 y 21). No obstante es una noticia aislada y, sobre todo, indeterminada. Lo más probable es que se relacione de algún modo con las minas de plata y plomo de Valdesisanz, en la vecina localidad de Calcena, principal centro de interés del de Morata en la zona, ${ }^{36}$ donde, además, se detecta en fechas muy próximas - 1560 - a un par de profesionales tudescos empleados en ellas. ${ }^{37}$ Con toda probabilidad serán los mismos.

\subsection{Tarazona (ferrería de Agramonte)}

De esta localización no contamos más que con una sola referencia. En 1458 Juan II, rey de Aragón, concede a la ciudad de Tarazona la prospección y aprovechamiento, en régimen exclusivo, de todo tipo de veneros metálicos dentro de su término y, señaladamente, en la porción sita en la falda del Moncayo, salvo los de oro y plata, que se reserva. El privilegio comprende las minas de hierro ya en funcionamiento, que la impresión que transmite el documento es que se trata de un hallazgo relativamente reciente, y las fabricas fargas, sive ferraras, a ellas vinculadas, que los turiasonenses han edificado

34 APNC, N. 78 , López Forcén, 1484, f. 193r-v.

35 APNC, N. ${ }^{\circ} 192$, Joan Remón, 1488, f. 126r-v.

36 El centro de su concesión es, precisamente, dicho barranco, abarcando una extensión de 7 leguas alrededor, Benedicto Gimeno y Mateos Royo, 2013: 39.

37 Los interesados figuran por entonces como habitantes de Trasobares. Publica el documento San Vicente Pino, 1988: Vol. I, 308, doc. 159. 
en Agramonte (publica el documento Sanz Artibucilla, 1930: T. II, 496-501), una pequeña localidad - 4 casas en el fogaje de 1495- encaramada en la ladera del Moncayo, que se despuebla hacia la segunda mitad del siglo XVII (Ubieto Arteta, 1984: Vol. I, 28). Tratándose de una concesión a un concejo, supongo que el fondo histórico del Ayuntamiento de Tarazona, que no he tenido ocasión de consultar, aportará más detalles sobre este yacimiento.

\subsection{Trasmoz (ferrería de La Mata de Castilviejo)}

Los datos referidos a Trasmoz son tardíos. En puridad, es posible rastrear alguna insinuación de fecha anterior, pero tan vaga que es imposible colegir nada firme. El diploma de la donación del término por el rey al noble Lope Ximénez de Urrea en 1437, por ejemplo, que comprende todo tipo de beneficios, incluidos los mineros, una especificación que, sin ser excepcional, tampoco se prodiga en los ejemplares aragoneses de esa tipología (publica el documento Sarasa Sánchez, 1977). Tal vez respondiese a alguna expectativa más o menos tangible. Recordemos igualmente los derechos inmemoriales que se atribuyen al concejo de Trasmoz, entre otras localidades de los contornos, para la explotación de las vetas férricas de su distrito en cierto pleito de principios del Seiscientos, del que ya hemos hablado anteriormente. Cabría pues dejar abierta la posibilidad de que en este lugar existió, quizás desde fechas remotas, algún tipo de aprovechamiento tradicional, del modelo que hemos visto para Ambel, pero nada más.

Dejando a un lado lo contingente, la referencia positiva más temprana que he podido localizar data del 10 de octubre de 1498, en que Fernando II concede a Pedro de Urrea, señor de Trasmoz, que prevé construir una ferrería en sus tierras, la facultad de buscar y abrir minas de hierro en cualquier lugar del reino de Aragón y, con tal fin, realizar las excavaciones, pozos y galerías necesarias, para así incrementar el provecho de la fundición. ${ }^{38}$

Al respecto, un par de puntualizaciones. Pedro Manuel de Urrea, que tal es su nombre completo, es el hijo menor - segundón- del primer conde de Aranda, promotor de la ferrería de Jarque pocos años atrás, como veíamos. Designado señor de Trasmoz en el testamento de su padre, que muere en 1490,

ACA, Cancillería, Reg. 3.572, f. 213r. El texto es accesible de forma directa a través de PARES (véase la dirección supra). Obtengo la referencia de Galé Casajús, 1997-1998: nota 24. Este documento debe ser, sin duda, al que vio en su día Gual Camarena, 1970: 281, para documentar las explotaciones de Trasmoz en 1498, aunque sin entrar en ningún tipo de precisiones ni dar referencia de origen. 
en 1498 Pedro de Urrea es menor de edad - cuenta con unos trece años - y dirige sus asuntos Catalina de Urrea e Hijar, su madre y tutora. ${ }^{39}$ Es ella, por supuesto, la que ha orquestado las gestiones que han culminado en la merced regia. Y Catalina tiene garantizados sus derechos de viudedad sobre las rentas y el dominio de, entre otros lugares, Jarque ${ }^{40}$ población donde además reside habitualmente. Demasiadas coincidencias. Todo apunta a que los resultados de la empresa de Jarque, de los que la Urrea tiene que tener un conocimiento muy directo, han sido lo bastante satisfactorios como para que la condesa viuda vea en la opción de repetir el experimento en Trasmoz una buena oportunidad para incrementar las rentas de su vástago más pequeño, por el que siente un afecto sincero. ${ }^{41}$

La ubicación elegida para la ferrería es la partida de La Mata de Castilviejo, un monte despoblado en las estribaciones del Moncayo incluido en la circunscripción de Trasmoz, a pesar de que está separado físicamente del resto del término municipal, formando un islote independiente, ${ }^{42}$ una situación que ha llegado a nuestros días. Al parecer, se trata de una fundación ex novo.$^{43} \mathrm{Un}$ par de años más tarde, la ferrería ya está levantada y Catalina de Urrea se preocupa de asegurarle el suministro de agua adecuado. Aunque el establecimiento se sirve ya del aforo del rio - más bien barranco - de Morca, que corre por

39 La biografía de este personaje, autor de una obra poética de cierta entidad, ha sido bien estudiada y documentada por Galé Casajús, 1997-1998, e id., 1999-2000.

40 Por dicho motivo, entre otros, mantuvo un pleito con el heredero del condado, su primogénito, fallado definitivamente a su favor en 1506, véase Galé Casajús, 1997-1998: nota 17. Con posterioridad a esa fecha se intitula en ocasiones como señora de Jarque, Galé Casajús, 1999-2000: 248 y 255, docs. 21 y 37.

41 Lo mantendrá hasta su muerte: en su último testamento, librado en 1521, lo nombrará su heredero universal, Galé Casajús, 1999-2000: 264 y ss., doc. 42. Pedro de Urrea le corresponde ampliamente, como queda en evidencia en su obra literaria, Galé Casajús, 1997-1998: 233.

42 Su posesión será objeto de disputa entre el señor de Trasmoz y su hermano Miguel Ximénez de Urrea, segundo conde de Aranda. El fallo, dictado por el propio rey Fernando el Católico en 1502, será favorable al primero, Galé Casajús, 1997-1998: 261 y ss., doc. 40.

43 Si ha habido algún precedente, es antiguo. En 1485 Ferrando de Montesa, mercader zaragozano, como procurador de Lope Ximénez de Urrea, futuro primer conde de Aranda, vende a Pedro Lázaro, escudero habitante de Borja, la lenya y fusta, assi verde como seca, de la partida de la Solana, en la deffessa clamada de La Mata de Castelbiejo, sitia a piet del Moncayo, así como toda las ramas y troncos caídos del conjunto de La Mata, por 4.200 ss. j. Si existiese alguna fundición en marcha en el lugar, este contrato es difícil que hubiera tenido lugar. Cabe consignar que, a la hora de ubicar la Solana en este contrato, se menciona otra porción de monte, enta las partes de Morana, que Pedro de Ogea, escudero habitante en Trasmoz, tiene comprometida - divisada, limitada y contractada para dar- con un vecino de Ágreda apellidado - el nombre se deja en blanco - Castejón, un patronímico muy vinculado a las cercanas minas de Vozmediano, en Castilla, como veremos seguidamente. APNZ, Antón de Abiego, notario de Épila, 1485, ff. 23v-25r. 
su territorio, no basta. ${ }^{44}$ A sus ruegos, el 1 de abril de 1500 las ciudades de Tarazona y Borja, la villa de Añón y la señora temporal de esta última, la encomienda hospitalaria de Ambel, autorizan a la condesa viuda de Aranda y a su hijo el paso de una acequia por el paraje denominado de Domingo Aznar, que es comunero de los otorgantes, con el fin de que puedan llevar el agua llamada de Val de Manzano - otro barranco cercano que desemboca en el de Morca, más abajo, dentro de la demarcación de Trasmoz - para las ferrerias que nuevamente se havian fecho et construido en La Mata de Castelbiejo. Evidentemente, la forja de La Mata es hidráulica. En 1504 - y seguramente algún año antes - debe estar ya plenamente operativa pues las capitulaciones matrimoniales de Pedro de Urrea, que se redactan por entonces, la incluyen entre los bienes que el señor de Trasmoz aporta a su matrimonio con María de Sesé, hermana de Manuel de Sesé, baile general de Aragón (Galé Casajús, 1997-1998: 253-256 y 268, docs. 28 y 51 respectivamente).

La explotación del taller, como era preceptivo, fue cedida en arriendo. Unos años más tarde hubo problemas con uno de los locatarios, el mercader zaragozano Francisco Morales de Santa Cruz, que intentaron solucionarse recurriendo a una sentencia arbitral librada en noviembre de 1518 (Galé Casajús, 1999-2000: 255-260, doc. 37). Aunque no tuvo efectos -el rentero se negó a aceptarla ${ }^{45}$ - se trata de un documento muy interesante en el que, a pesar de que sobrepasa ligeramente el marco cronológico de nuestro estudio, merece la pena detenerse.

De acuerdo con este texto, la gestión de Morales y sus ministros ha sido nefasta: han dejado deteriorarse las instalaciones -ferrerias, casas, açudes, canales, cequias e presas - , las cuales, en el momento de dictarse la sentencia, se hallan derribadas e muy derruidas e perdidas; pudrirse importantes partidas de leña y carbón; degradar el monte de La Mata, por no se cortar como se debia cortar y que además se ha incendiado en parte; como colofón, se han marchado a laborar a la vecina ferrería de Añón, hacia comienzos del año en curso - los plazos vencidos del año 1518 están pendientes de cobro en

44 El régimen de aprovechamiento de este curso y el de su tributario, el Valdefaya o Valdefoya, por parte de los concejos de Trasmoz y Litago, es fijado, por sentencia arbitral, en 1511. El texto precisa que el Morca, tras su nacimiento, traspasa los límites de La Mata y de alli el dicho rio va junto y da en las ferrerias vulgarmente clamadas de La Mata, las quales ferrerias son del dicho señor don Pedro Manuel de Urrea y se administran aquellas con el agua del dicho rio de Morca. Galé Casajús, 1997-1998: 85, doc. 78 .

45 El pleito se arrastraba todavía en 1524, Galé Casajús, 1999-2000: 269, doc. 48. 
su mayor parte - , llevándose todos los utensilios y herramientas de la de Trasmoz, que dejan abandonada a su suerte. La razón aducida por el arrendatario es el incumplimiento de los compromisos asumidos por el propietario y en concreto el suministro de bena. No obstante, la sentencia aclara que no hay tal, pues esa comisión quedó, a partir de la muerte de Apert - un apelativo de inequívoco acento foráneo-, benaquero del dicho señor don Pedro, en manos del zaragozano y los suyos, los cuales escondieron aquella con malas intenciones. De hecho, a los árbitros les consta que María de Sesé, señora de Trasmoz, en el momento en que surgió el litigio, envió a sus benaqueros a las beneras y aquellos hallaron la bena ascondida.

Pero lo más importante de este testimonio es que nos da cifras: la indemnización por el menoscabo de los recursos forestales se calcula en 600 ducados; la satisfacción por los daños en las infraestructuras en 10.000 ss. j.; la pena prevista si no se devuelven los pertrechos sustraídos - junques, çobras, machos, martillos, tenaças, porgaderos ${ }^{46}$ - en 1.000 ducados de oro, equivalentes a $22.000 \mathrm{ss} . \mathrm{j}$. Aunque no hay que tomarse estas cantidades al pie de la letra, pues incluyen con toda probabilidad un plus distorsionador de carácter conminatorio y/o punitivo, transmiten muy bien lo que significaba económicamente la puesta en marcha y el alimento de la actividad de estos ingenios.

La sentencia de 1518 también nos revela las condiciones del arriendo: una duración de treinta años, a contar de la fecha de formalización — diciembre de 1511 - , por un monto de 324 qs. y una arroba de hierro anuales. Son unas cláusulas inusuales: el plazo temporal es extraordinariamente $\operatorname{largo}^{47} \mathrm{y}$ el devengo, a priori, desproporcionado. ${ }^{48}$ Aunque desconociendo el resto del arti-

46 En otra alusión de la sentencia enclusa, machos, martillos, manchas, tenaças.

47 En Guipúzcoa, por ejemplo, el promedio no llega a los cinco años y la duración más larga de todos los arriendos registrados para los siglos XV y XVI es de 16. Plazos tan dilatados eran excepcionales y solían obedecer a necesidades perentorias del dueño, conllevando habitualmente un importante adelanto de la renta. Díez de Salazar, 1983: Vol. I, 239. Podría ser el caso: tras mudar su residencia a Trasmoz hacia 1510, Pedro Manuel de Urrea se vio envuelto en una serie de enfrentamientos violentos con los lugares vecinos que degeneraron en 1512-1513 en una auténtica guerra abierta, dentro del marco general de las luchas banderizas entre los Urrea y los Aragón que desgarraron el reino aquellos años ( $c f$. Galé Casajús, 1999-2000: 231 y ss.), una coyuntura en la que es muy fácil que el señor de Trasmoz precisase de liquidez inmediata.

48 Por estas mismas fechas los propietarios de las ferrerías del río Hoceseca, en el señorío de Molina, también en la cordillera Ibérica, percibían unas rentas que, aunque no conocemos con toda exactitud - la fuente es procesal y los datos reflejados son, conforme a lo acostumbrado en este tipo de documentación, contradictorios - , nunca fueron superiores a 200 qs. por establecimiento y ejercicio, Cortés Ruiz, 1996. Esta cifra concuerda con las primeras previsiones para la cesión de la ferrería de Jarque en 1488, que hemos visto anteriormente: alrededor de 150 qs. En Guipúzcoa, la caída de los arriendos en 
culado contractual, resulta imposible realizar valoraciones ponderadas, habla muy elocuentemente de que la contratación se realizó en unas circunstancias poco corrientes pero, sobre todo, de una producción global muy apreciable, que muy posiblemente haya que poner en relación con la existencia en La Mata, si no de más de un centro productor, de dos hornos.

La fábrica de Trasmoz consiguió recuperarse de sus quebrantos. En 1524 su estado era lo suficientemente bueno como para justificar que María Sesé, viuda de Pedro Manuel de Urrea - fallecido en 1521 - , y su hijo, Lope de Urrea, rivalizasen por su causa (Galé Casajús, 1999-2000: 269-270, doc. 49). A mediados de siglo se encontraba totalmente operativa. En 1549 y en 1554 las ferrerías son comprometidas como garantía del pago de sendos censales que toman Lope Ximénez de Urrea, titular de la jurisdicción de Trasmoz, y el concejo del lugar, ${ }^{49}$ mientras que en 1552 el señor de Trasmoz conviene con cinco metaleros zaragozanos el suministro de 250 qs. de hierro de la forja de La Mata, a librar en dicha ciudad a razón de 25 al mes, por un precio unitario de 41 ss. j. (San Vicente Pino, 1988: Vol. I, 239-240, doc. 133). La labranza férrica sobrevive en Trasmoz durante los siglos XVII y XVIII. ${ }^{50}$

\subsection{La vertiente castellana}

En 1417 Juan II, rey de Castilla, en una de las raras ocasiones en que los soberanos peninsulares tomaron la iniciativa en materia minera durante el Medievo, comisiona a una serie de maestros para que reconozcan sus reinos en búsqueda de yacimientos aprovechables. En sus exploraciones, estos prospectores llegan hasta la parte castellana del Moncayo, donde constatan labores de minería férrica y así lo hacen figurar en el informe de los resultados de su expedición que elevan al monarca (Sánchez Gómez, 1990: 110). A fines de la centuria tenemos constancia de dos fundiciones en marcha en la zona: Aravia-

las primeras décadas del Cuatrocientos motivó que las ordenanzas de los ferrones del valle de Mendaro estatuyeran en 1442 el límite mínimo de los mismos en un $10 \%$ de los rendimientos, pauta que fue la norma durante el resto del siglo XV y buena parte del XVI según Díez de Salazar, 1983: Vol. I, 230 233. Las escasos datos conocidos sobre las rentas generadas por las fundiciones guipuzcoanas durante el Quinientos señalan valores equivalentes a en torno los 100 qs. anuales y menos, id.: 240 y ss.

49 Archivo Histórico Nacional (AHN), Clero, Cartuja de la Concepción de Zaragoza, Carp. 3.799, N. ${ }^{\circ} 6$ y 8 , respectivamente.

50 A principios del siglo XVII la mina de hierro de Trasmoz es una de las mencionadas por Ximénez de Aragués, 1630: 98. En el Setecientos la ferrería ha pasado a formar parte del patrimonio del concejo, Benedicto Gimeno y Mateos Royo, 2013: 219 y 278. 
na, una localidad junto al río del mismo nombre, hoy despoblada e incluida en el término de Beratón, y Vozmediano.

En la primera trabajan los vizcaínos Joan de Artubiaga, atora, ${ }^{51}$ e Iñigo de Elvira, habitantes en dicha ferrería del regno de Castilla, que el 9 de abril de 1481 venden en Calatayud a Joan Daca, mayor, hijo de Miguel Daca, ciudadano de la misma, 90 qs. de hierro - quintal mayor, de XXXVI libras [la] rova ${ }^{52}$-, puestos en la capital del Jalón de aquí a Santa María de agosto, a razón de 6 qs. semanales, por 17 ss. 8 ds. j. la unidad. Corren por cuenta de los productores el transporte y todos los gastos, incluido el abono de las tasas aduaneras del General, salvo los derechos de peso, peaje y corredurías, que quedan a cargo del comprador. Queda convenido que, si alguna semana falla el envío, su monto se acumula para la siguiente y que el tomador se compromete a recibir el dicho hierro en cualquier circunstancia, so pena de 10 florines. Inmediatamente a continuación, los dos vendedores toman en comanda de Joan Daca 15 florines, percibidos seguramente como señal. ${ }^{53}$

Poco después, el 8 de septiembre de 1484, son Pedro López, hijo de Pedro López, y Pedro Budari, también ferreros vizcaínos, habitantes de present en dicha ferrería, los que se obligan en Calatayud. En esta ocasión, con el hostalero bilbilitano Martín de Chovarruvia del que toman en comanda 11 florines, cuya devolución garantizan sobre un mulo de pelo rucio. ${ }^{54}$ Prospecciones arqueológicas recientes han localizado en el antiguo término de Araviana potentes escoriales férricos y varios hornos de reducción datados en época celtibérica, aunque sin excluir cronologías posteriores, romanas o medievales. Uno de ellos, sin embargo, es seguro de época bajomedieval o moderna pues utilizó energía hidráulica - un procedimiento desconocido en la Antigüedad mediante una infraestructura de cierto aparato: una acequia de unos $5 \mathrm{~km}$ de longitud que traía el agua desde la vecina población de Cuevas de Ágreda (Sanz Pérez et alii, 2001), en atención a que el «río» Araviana es inhábil para esos menesteres, pues está seco la mayor parte del año.

51 En euskera, viene a equivaler a «hidalgo». Este Joan de Artubiaga es seguramente el Joan de Arturiaga que, más arriba, hemos visto residiendo en la forja de Purujosa en 1483.

52 En atención al origen castellano del metal, el redactor, para evitar confusiones, está especificando la magnitud ponderal usual del quintal férrico en Aragón. En la relación de pesos y medidas que se añade a las ordenanzas de la cofradía de mercaderes de Huesca de 1416 se lee: fierro y es XXXVI livras la rova, Falcón Pérez, 1997: 194, doc. 113. El quintal aragonés equivale a 50,52 kg, Lara Izquierdo, 1984.

53 APNC, N. ${ }^{\circ} 185$, Joan Remón, 1481, f. 40r-v.

54 APNC, N. ${ }^{\circ} 188$, Joan Remón, 1484, f. 323v. 
En cuanto a Vozmediano, el arranque de su industria se remonta, como poco, a la primera mitad del Cuatrocientos. El 15 de abril de 1477 los reyes de Castilla conceden a su maestresala, Lope de Valdivieso, una importante merced: la explotación de todas las meneras de las estribaciones castellanas del Moncayo ${ }^{55}$ lo que de forma prácticamente inmediata - aquel mismo añomotiva las protestas de García de Castejón o Castrejón, vecino de Ágreda, en su nombre y en el de su madre y hermanos. Según este personaje, Juan Ruiz de Ágreda - calificado alternativamente de su tio o su abuelo-, alcaide que fue de la fortaleza de Vozmediano durante los reinados de Juan II de Castilla (1406-1454) y Enrique IV (1454-1474), construyó hace unos cuarenta años, poco mas o menos, cerca de dicho castillo, en el Vale de Valdies - actual barranco de Valdiez-, unas ferrerias del lab[r]ar fierro a las que alimentó con la vena de los yacimientos de los alrededores, que tuvo siempre como suyos y como tal legó a su heredero, Diego Ruiz de Agreda, el cual las poseyó igualmente. Tras el fallecimiento de Diego Ruiz, que también ostentó el alcaidado de Vozmediano, estas veneras pasaron al reclamante y sus parientes. Obviamente, la concesión otorgada a Valdivieso les perjudica, y mucho, desencadenando el correspondiente pleito, del que tenemos diversas noticias para los años 1477-1480, aunque desconocemos su conclusión. ${ }^{56}$

No es el único problema al que tienen que enfrentarse los Castejón, contra los que, en 1483, promueven una causa judicial Juan Ruiz de la Mata y su hermana Teresa, vecinos de Agreda, que alegan derechos sobre los bienes del citado Juan Ruiz de Agreda, incluidas las ferrerias de Vuxmediano. ${ }^{57}$ La querella todavía persiste en $1494 .^{58}$

55 Fue el primero de los sucesivos intentos - fracasados - de la monarquía de racionalizar la producción minera en las sierras ibéricas mediante la creación de grandes distritos, en el Moncayo y en las sierras de Molina, cedidos a grandes personalidades de la nobleza cortesana. El objetivo era, en primer término, recompensar lealtades políticas, pero también propiciar la revitalización de la extracción, confiando en que estos dignatarios, titulares de grandes fortunas, realizasen las inversiones necesarias susceptibles de modernizar y ampliar las explotaciones. Benedicto Gimeno y Mateos Royo, 2013: 172 y ss.

56 Archivo General de Simancas (AGS), Registro General del Sello (RGS), Legs.: 147.712, 484 (1512-1477); 147.909, 118 (2-9-1479); 147.908, 82 (7-8-1479); 148.006, 51 (14-6-1480); 148.011, 112 (11-11-1480). Tengo noticia de la mayoría de estas referencias a través de Benedicto Gimeno y Mateos Royo, 2013: 26, en nota.

57 AGS, RGS, Leg. 148.312, 77 .

58 AGS, RGS, Leg. 149.403, 471. En este documento de habla de las ferrerias de Valdias. Este texto, como los anteriores, puede consultarse en línea a través del portal PARES (véase la dirección supra). Sobre este litigio hay más información, tanto en el AGS como en el Archivo de la Chancillería de Valladolid. 
Pero estas incidencias no interfieren en el funcionamiento de las ferrerías, que, a fines del Cuatrocientos, presentan un estimable índice productivo con una fuerte proyección hacia el mercado aragonés. El 9 de septiembre de 1485 comparece en Zaragoza ante el mercader Joan Francés, habitante de presente en dicha ciudad, Alonso Daca, procurador del senyor de las ferrerías de Vozmediano, Joan González de Castejón, tal vez uno de los hermanos de García de Castejón. Según expone, el dicho su principal suscribió con Francés cierta concordia por la que le vendía 1.000 qs. de hierro a 14 ss./q., a librar en Borja, pessados en el pesso del rey, a razón de 9 qs. semanales - lo que supone un plazo de cumplimiento de algo más de dos años-, entre otras condiciones que desgraciadamente no puntualiza. Hasta el presente, el suministrador ha cumplido escrupulosamente su parte, sostiene su representante, y aún ha dado en cada rova seys livras mas que dar vos devia, lo que motiva que solicite al comprador benir a conto y solventar cualquier posible diferencia que pudiese haber. Si este se niega, Castejón suspenderá el cumplimiento del acuerdo imputando cualquier posible perjuicio al marchante.$^{59}$ No sabemos cómo acabó el asunto.

Estas transacciones debieron prolongarse los años siguientes: en 1492, como veíamos anteriormente, la forja de Vozmediano, en connivencia con la de Añón - una asociación un tanto extraña-, enviaba directamente hierro a Zaragoza. Pero las relaciones eran bilaterales: los Castejón no solamente dan salida a su producción en el reino vecino, también se proveen de leña; en 1484 uno de los miembros del linaje tenía acotada una partida de monte en La Mata de Castilviejo, lista para su uso. ${ }^{60}$

No he hallado vestigios confirmados de actividad siderúrgica en el Moncayo castellano para los siglos modernos. Según Benedicto Gimeno y Mateos Royo, 2013: 47-48 y 187, las ferrerías de esta vertiente cerraron muy tempranamente, tal vez a principios del siglo XVI, a causa de sus menores disponibilidades hidráulicas en comparación con sus competidoras del otro lado del macizo - el escarpe castellano es mucho más seco que el aragonés-, que fueron las que acabaron absorbiendo todo el trabajo de fundición del territo-

59 APNZ, Pueblos N. . 87, Pedro Pérez, 1485. En rigor en la carta se lee ferrerias de Puxmediana. Pero, considerando que no encuentro ningún nominal en la zona que se ajuste plenamente a esa nomenclatura y que hay pruebas documentales sólidas de que Joan González de Castejón fue vecino de Ágreda a fines del siglo XV - véase AGS, RGS, Legs. 149.108, 249 (26-8-1491); 149.107, 130 (14-7-1491); etc. - , quiero pensar que se trata del lapsus de un escribano zaragozano poco familiarizado con la toponimia del Moncayo.

60 Véase nota 43. 
rio. Sí en cambio hay evidencias de que la extracción continuó e incluso se denunciaron nuevas concesiones en Ólvega, Beratón, Cuevas de Agreda (Larruga Boneta, 1792: 98 y 101; González Carvajal, 1832: 29-30, 283 y 557559)... que no obstante no siempre se plasmaron en explotaciones operativas, al menos de forma inmediata (Sánchez Gómez, 1990: 239).

\section{Una visión global diacrónica}

Aunque la evidencia documental es mínima - las dos sentencias de Ambel-, es patente que el Moncayo produce hierro para el mercado ya a mediados del Doscientos, aunque utilizando una tecnología muy atávica si hemos de juzgar por el único caso conocido. Y seguramente también antes y con una extensión territorial más amplia que la encomienda templaria de Ambel, como insinúan algunos indicios.

La toponimia coetánea, por ejemplo. En 1179 tiene lugar la compraventa entre unos particulares de una viña sita en el termino de Herrarera, a la parte de oriente del brazal que va al baño del burgo de Tarazona (Kiviharju, 1989: 37, doc. 18). Poco antes, en 1177, el rey Alfonso II confirmaba al monasterio de Veruela una serie de daciones anteriores, entre ellas donationem illam de Ferraria, quam fecit rex Sancius - Sancho VI de Navarra (1150-1194) - et comes pater meus -Ramón Berenguer IV, conde de Barcelona y príncipe de Aragón (1137-1162) - , con su término (Sánchez Casabón, 1995: 325, doc. 236). Debía tratarse de un pequeño asentamiento ${ }^{61}$ situado, según cabe deducir del listado de sus mojones ${ }^{62}$ en las cercanías de las denominadas Peñas de Herrera, jalón de la actual circunscripción municipal de Talamantes con Añón, Calcena y Purujosa. Una de estas Peñas era conocida como Ferrellón ya en 1188 (Sánchez Casabón, 1995: 645, doc. 484). Sobre ella se construirá poco después - si es que no existía ya - un castillo que en 1200 Pedro II cedía al monasterio de Veruela con la condición de que lo mantuviera bien custodiado y fortificado (Alvira Cabrer e Ibarra y Oroz, 2010: doc. 256). En 1231 Jaime I daba en prenda de cierto préstamo que había recibido del monarca navarro Sancho VIII una serie de fortale-

61 A fines del siglo XVIII, el anónimo redactor del manuscrito denominado convencionalmente Libro Registro de Veruela - que viene a ser un índice extenso, organizado por temas, de todos los documentos que conservaba el archivo del monasterio por entonces - lo moteja de granja. Cabanes Pecourt, 1985: 12.

62 A Pinna Serrada usque a Calarizos de Calçena et Foi de Boida et vallem de Avellana a Forricella in intrus et vallem de Linars cum Trevigno intro stantibus. Vid. la referencia supra. 
zas, entre otras, las de Ferrellón y Ferrera, incluidos sus derechos e con los omes e con las mulleres que aqui estan ni d'aqui adelant seran (Marichalar, 1934: doc. 176). Este último baluarte se sitúa en el punto más alto de las Peñas de Herrera, muy cerca del anterior. ${ }^{63}$ Como es lógico con estos antecedentes, la cárcava que nace en las faldas de esta sierra, ya en el distrito de Talamantes, se nombra como Valdeherrera, apelativo que encuentro citado por primera vez en 1283 (Kiviharju, 1989: 84 y ss., doc. 65), aunque con toda probabilidad, dada su filiación, será más antiguo. En el término de Añón, casi frente por frente del caserío, se registra el monte del Escorial, mencionado en la carta de población de la vecina Alcalá de Moncayo de 1238. Etc. ${ }^{64}$

En un terreno más tangible, cabe aludir al florecimiento de las forjas de la cercana Calatayud, cuyas rentas en 1219 son ya lo bastante sustanciosas como para servir de moneda de cambio en cierta permuta entre el monarca y el monasterio de Piedra. ${ }^{65}$ Y su entidad va creciendo con el tiempo: en 1249 el rey Jaime I prohíbe a los hombres de Calatayud utilizar otras fabricam ferrarie que no sean las que Piedra posee en la ciudad, en función de la cesión anterior, seguramente intentando bloquear la apertura de nuevas fraguas que están surgiendo fuera del control del cenobio. ${ }^{66}$ La misma situación que en el mundo celtíbero-romano y, tal vez, por las mismas causas: un suministro de materia prima significado procedente de las serranías ibéricas.

63 Véase Gutiérrez López, 2005: 35-38, que acopia las noticias históricas sobre los castillos de Ferrellón y Ferrara - aunque sin pormenorizar las procedencias - y hace una buena descripción de sus restos materiales. Al de Ferrellón dedica dos artículos monográficos Rodríguez Lajusticia, 2005 y 2008, respectivamente.

64 Con esa nomenclatura se identifica la parte de terreno que se beneficia de un turno de riego desde el azud, Ledesma Rubio, 1991: 221, doc. 178. En efecto, el collado del Escorial se sitúa a la vera del barranco de Morana, un curso de agua muy disputado entre las poblaciones y poderes feudales ribereños. Desde luego existen en las sierras del Moncayo hoy en día muchos más nombres geográficos que denotan actividades de este tipo: el prado de Herrera, cerca de las cumbres, en el término de Añón; las Minas, una elevación en el mismo municipio; el brazal de la Ferrera, en el de Tarazona; el monte de la Carbonera, próximo a Vozmediano; Valdehierro, Valdehierros de la Caldera y Valdehierros de la Cueva en las cercanías de Cuevas de Agreda... No obstante, dada la prolongación de las labores férricas en la zona hasta prácticamente la actualidad, resulta muy arriesgado atribuirlas a una época u otra sin base documental, una investigación con entidad por sí misma que está por hacer y que excede, con mucho, los propósitos del presente trabajo.

65 El convento, contra la entrega a Jaime I de la villa de Villafeliche, obtiene todas las tiendas y obradores, con mención expresa de los metálicos - operatoriis...fabrorum-, que el rey posee en la alcaicería de Calatayud más las salinas de Abanto y Monterde y una viña en Daroca. Publica el texto Huici Miranda y Cabanes Pecourt, 1976: Vol. I, doc. 21.

66 El mandato se aplica, aparte de a las ferrerías, a las tablas de cambio, la tintorería y las tiendas en general. Id.: Vol. II, doc. 510. 
Otra pista a tener en consideración es la importancia local de un ramo tan delatador como la carbonería, íntimamente unido en el universo tradicional a los oficios del fuego y, muy especialmente, a la siderurgia ${ }^{67}$ En una fecha tan temprana como 1148, un acuerdo de delimitación de términos entre Ambel y Traid - un enclave que se despoblará posteriormente integrándose en el término de Alcalá de Moncayo - utiliza como referencia un paraje nombrado como corte de Carbonere (Ledesma Rubio, 1991: 95, doc. 70). En 1234 Jaime I, rey de Aragón concede a Veruela el encinar de Vera y la granja de Traid, para que sirvan de dehesa para sus ganados, más el vedado de Maderuela, en este último caso prohibiendo que nadie corte madera ni haga carbón sin consentimiento de los monjes (Huici Miranda y Cabanes Pecourt, 1976: Vol. I, doc. 200). La medida no surte efecto: a mediados de siglo los hombres de Trasmoz devastan el monte de Maderuela, cuya propiedad pretenden, siendo por ellos excomulgados y condenados judicialmente en 1251 y $1252 .{ }^{68}$ En 1238 la comunidad monástica concede carta de población a la villa de Alcalá de Moncayo, un texto que no identifica más que dos ocupaciones no relacionadas con el sector agropecuario: la de tejedor y, precisamente, la de carbonero.$^{69} \mathrm{El}$ detalle de esta ocupación es rarísima en la tipología documental antedicha, en Aragón por lo menos. En 1246 se toma declaración a varios testigos acerca de los derechos del monasterio para leñar y carbonear en Val de Abella, Val de Linares, Val de Avellano, Val de Morana y Val de Manzano, partidas de los términos de Añón y Talamantes. ${ }^{70}$ Cabe concluir que el carbón vegetal era un sector pujante en aquellos contornos. Desde luego, se trata de un producto muy consumido en el mundo medieval y preindustrial en general que, cuando se desarrollen plenamente las redes comerciales, será objeto de un fuerte tráfico. ${ }^{71}$ Pero para este momento, en que todavía están terminando de cuajar los espacios econó-

67 Es interesante consignar que, en las ocasiones en que la arqueología ha dado con talleres medievales de herrería convencional, no se ha podido constatar la presencia de depósitos de carbón. Al parecer, el combustible utilizado de forma sistemática era la madera. En las fargas sucede sin embargo lo contrario, pues solamente el carbón permite alcanzar las temperaturas necesarias para la reducción del hierro. Sancho i Planas, 2011: 658, nota 43.

68 AHN, Clero, Monasterio de Santa María de Veruela, Carp. 3.767, N. ${ }^{\circ}$ 14, y Carp. 3.763, N. ${ }^{2}$. Véase también Cabanes Pecourt, 1985: 41.

69 Concretamente, con ocasión de la estimación del diezmo eclesiástico: a los tejedores se les adjudica una cuota fija anual de 2 ss. y a los carboneros de 12 ds. Ledesma Rubio, 1991: 221, doc. 178.

70 AHN, Clero, Monasterio de Santa María de Veruela, Carp. 3.767, N. . 7. Ho he visto el documento directamente. La alusión al carboneo la tomo de Blanco Trías, 1949: 86.

71 El ejemplo del Sur de Aragón a mediados del Cuatrocientos, donde cada año salen hacia Valencia varias decenas de toneladas de carbón vegetal, es muy ilustrativo. Villanueva Morte, 2005: Vol. II, 210-211. 
micos interiores, esta prevalencia tiene que estar en relación, como mínimo en parte, con una demanda endógena que solamente puede provenir de las necesidades metalúrgicas locales.

En suma, a tenor de lo expuesto, hay argumentos para sostener que en el Moncayo hay una tradición de laboreo férrico espacialmente diseminada que, en función de los guiños de la toponimia, se retrotrae hasta el siglo XII, como poco ${ }^{72}$ y que esta corriente, hasta donde podemos verificar, alcanza en la primera mitad del Doscientos el suficiente desarrollo como para traspasar los límites del mero autoabastecimiento local. Lo llamativo es que en este panorama, presuntamente dominado por prácticas y usos ancestrales en régimen cerrado, se implementan a partir de mediados del siglo XIII una serie de nuevas instalaciones promovidas por unos agentes totalmente diferentes: el rey - un sujeto, insisto, muy poco inclinado a intervenir directamente en estos negocios - , el poder señorial e incluso lo que podría ser un maestro del ramo foráneo. No tenemos el menor indicio acerca de su naturaleza, salvo que tienen el porte, la estabilidad y el atractivo económico suficientes como para justificar, en el caso de Jarque, la solicitud de la anuencia regia y, en los de Añón y Trasobares, una serie de roces, bastante agrios, a principios de la década de 1280, entre la monarquía y las autoridades feudales autóctonas. No son las actitudes que cabría esperar ante una tecnología de las características de los rudimentarios hornos de reducción directa. Teniendo en cuenta que la segunda mitad del Doscientos es el periodo en que, paralelamente a un notable incremento del interés de las clases dominantes por el fomento de la explotación del subsuelo, ${ }^{73}$ empieza a introducirse el uso de la fuerza hidráulica en la

72 Resulta tentador dilatar la explotación férrica del Moncayo hasta época andalusí, en particular teniendo presente el paralelo de Sierra Menera, vid. supra. Pero, ciertamente, eso no pasa de ser un mero brindis al sol en el estado actual de nuestros conocimientos. No obstante, si alguna vez se explora esa posibilidad, hay que partir de la base de que, aun confirmándose, sus resultados serían poco espectaculares pues ni siquiera bastarían para cubrir las necesidades del valle medio del Ebro, que no debían ser por entonces particularmente voluminosas. En el último tercio del siglo XII, Alfonso II de Aragón (1164-1196), establece un arancel que grava la circulación de una serie de mercancías - entre ellas, el hierro - que se transportaban, en su inmensa mayoría, Ebro arriba, desde la costa mediterránea. Como razona Sesma Muñoz, 2009: 31-33, lo más probable es que ese peaje no sea más que la revalidación de otro más antiguo, promulgado originalmente por al-Muqtadir, rey de la taifa zaragozana (1046-1081).

73 Véase el acopio de informaciones referidas al Pirineo reunido por Mugueta Moreno, 2009: 12, nota 9. Complétese, para Aragón, con Utrilla Utrilla, Laliena Corbera y Navarro Espinach, 2006: 40-42. El lapso 1259-1264 fue especialmente febril. Durante esos seis años Jaime I expide otros tantos permisos para la prospección y puesta en marcha de minas - incluido el de Jarque que hemos comentado - y cinco más para la búsqueda de tesoros, un número muy alto para lo que es el ritmo habitual de emisión de estas patentes en la corte aragonesa. Palacios Martín, 1977: 284-285. Una de esas licencias para el 
siderurgia en la mayoría de los espacios hispánicos y sus aledaños — de momento solamente en su aplicación de martinete ${ }^{74}-$, lo más plausible es que la fisonomía novedosa de los talleres que se abren en el Moncayo contemporáneamente obedezca a la penetración de esa flamante tecnología.

Abona esta idea el fuerte repunte de las pugnas por los aprovechamientos forestales que tiene lugar en el contexto, en una coincidencia espacial y temporal tan ajustada, que es difícil de creer que sea casual. El conflicto que veíamos en 1246 entre el monasterio de Veruela y los concejos de Añón y Talamantes por los derechos de leñar y pasturar en una serie de pequeños valles del contorno reverdece con fuerza justo los mismos años en que se funda la ferrería de Añón. Pero con una elocuente novedad: junto a los municipios se alinea la orden del Hospital. El enfrentamiento debe alcanzar cotas serias pues sus ecos llegan a la corte ${ }^{75} \mathrm{y}$, cuando las partes convienen poner el pleito en manos de unos árbitros mediadores, uno de los elegidos es del máximo nivel: Pedro Martínez de Artasona, justicia de Aragón. El fallo se dicta en 1283 (Kiviharju, 1989: 84-88, doc. 65).

Desgraciadamente, a partir de este punto el bloque de información reunido observa un vacío importantísimo, que abarca todo el siglo XIV y, prácticamente, la primera mitad del siglo XV, lapso durante el que cabe presumir algún tipo de perduración de estas actividades, según sugiere la noticia aislada

hallazgo de tesoros interesó al Moncayo: la librada en 1261, válida para el término de Tarazona, a favor de Blasco Pérez, sacristán de la iglesia de dicha ciudad, un personaje de tintes sombríos que en 1267 era juzgado por falsificador de moneda y condenado a cadena perpetua, Canellas López, 1977.

74 En el Bierzo, ya en 1245, se habla de molineras junto a un río relacionadas con el trabajo de una menera de hierro, Balboa de Paz, 1990: 17. El primer testimonio documental de ferrerías hidráulicas en el País Vasco es de 1290, Urteaga Artigas, 1996: 543-558. Pero considerando el gran volumen de hierro exportado por los puertos guipuzcoanos por esos mismos años es obvio que tienen que ser anteriores en varias décadas, Bilbao Bilbao, 1987: 63. En Navarra las alusiones a ferrones más tempranas son de 1280 , retrasándose las relativas al uso de la fuerza hidráulica a principios del siglo XIV, Mugueta Moreno, 2009: 13-15. En Bearne, el primer mouline à fer plenamente atestiguado es de 1299, Verna, 2001: 167-168. En Aragón, la referencia documental más antigua se localiza en un diploma real, despachado en 1309, que autoriza la erección de una molina seu ferrarie en Bielsa, Bielza de Ory et alii, 1986: 191. Etc. Evidentemente, estas datas deben entenderse como meros jalones ante quem. El advenimiento efectivo sería casi siempre anterior en lapsos que pueden ser notables, como veíamos en el caso vasco. La única excepción reseñable podría ser Cataluña donde la mecanización hidráulica se difunde a partir del siglo X, según Sancho i Planas, 2011: especialmente 663-664 (la autora ha abordado la cuestión en otros trabajos anteriores que, por simplificar, omito). Esta cronología no es compartida por diferentes historiadores franceses que retrasan su aparición hasta el siglo XII y su propagación a la centuria siguiente, véase en id:: 656 .

75 Rodríguez Lajusticia, 2010: 119, nota 220, señala que en los registros de la cancillería aragonesa hay abundante información sobre este episodio. 
de las minas en la vertiente castellana de 1417, que consignábamos más arriba, y algunas referencias puntuales sobre el carboneo, industria que sigue manteniendo su dinamismo en la comarca. ${ }^{76}$ Aunque hay que admitir que, objetivamente, son unas pruebas tan parcas como débiles.

Pero fuera cual fuese esa evolución, lo que sí es patente es que a mediados del siglo XV su balance es muy deslucido. Los libros de collidas del impuesto aduanero aragonés del General de mediados del siglo XV no consignan entradas y salidas de material férrico en bruto en la frontera castellanoaragonesa del Moncayo y sus aledaños más que de forma anecdótica — tan solo algo de acero por Tarazona ${ }^{77}-$, lo que, en primera instancia, remite a una situación anodina, incompatible con la extensión de complejos siderúrgicos de algún rango a uno y otro lado de la divisoria. Contemporáneamente, en el reino de Aragón la dependencia de las importaciones férricas procedentes, sobre todo de Navarra y el País Vasco, ${ }^{78}$ pero también de la costa mediterránea - acero, en particular ${ }^{79}$ - , parece muy sustancial. La debilidad del sector, en el conjun-

76 La carta puebla otorgada por el cenobio verolense a Vera del Moncayo en 1368 para favorecer la repoblación del lugar, abandonado durante la Guerra de los Dos Pedros, vuelve a contemplar a la hora de abordar el pago del diezmo el oficio de carbonero, como en la de Alcalá del Moncayo 130 años antes - vid. nota 69-, aunque esta vez sin precisar ninguna cuantía sino remitiendo, reveladoramente, a la costump en Anyon. Pocos años después, en 1380, los monjes confirman, con el mismo objeto, la carta de Alcalá, sin variaciones significativas. Ledesma Rubio, 1991: 312 y 315-316, docs. 244 y 245, respectivamente. En 1436 la ciudad de Tarazona concede al monasterio de Veruela y a sus vasallos de Litago la potestad de pacer, abrevar, leñar y carbonear en algunas partidas que le pertenecen de la Dehesa del Moncayo. AHN, Clero, Monasterio de Santa María de Veruela, Carp. 3.785, N. 9 y 10. Véase también Cabanes Pecourt, 1985: 93.

77 De los libros de las Generalidades de cerca de cincuenta tablas dispersas por todo el territorio aragonés - seis en la zona del Moncayo: Ariza, Calatayud, Moros, Aniñón, Aranda y Tarazona - manejados por Sesma Muñoz y Líbano Zumalacárregui, 1982, solamente hay referencias al hierro en los de Aínsa, Valbona, Barracas, Monzón, Zaragoza, Albalate, Fraga y Monroyo (p. 204) y al acero en los de Aínsa, Huesca, Tarazona, Monzón, Monroyo, Arens de Lledó, Alcañiz, Barracas, Escatrón, Jaca, el Real, Torla y Zaragoza (p. 66). De las tablas cercanas al Moncayo, el único de esos registros que ha sido estudiado monográficamente es el correspondiente al ejercicio de 1445-1446 de Calatayud: García Herrero, 1983, y García Herrero, 1984. Confirma lo anterior: aunque es muy frecuente el paso de objetos metálicos obrados (armas, herramientas, utensilios...), en toda la anualidad solamente se consigna, anecdóticamente, el paso de una partida de hierro de Flandes, id. 1984: 381. Estos resultados son solamente un muestreo. El General tenía en la sobrecollida de Tarazona-Calatayud - la demarcación que abarcaba la frontera castellanoaragonesa desde el Moncayo hasta la actual provincia de Guadalajara36 puestos de control y recaudación en 1453, Sesma Muñoz, 1976: 124. De todos ellos subsisten libros de collida para mediados del Cuatrocientos, cuyo análisis, con las salvedades señaladas, está pendiente. Pero no cabe esperar grandes novedades: las tablas más importantes, las de Tarazona, Calatayud y Ariza, son las que más atención han recibido.

78 Véase nota 5.

79 Por la aduana de Barracas entran en Aragón desde Valencia durante los ejercicios fiscales de 1444 1447 la considerable cantidad de 239 balons de acero - una unidad de medida específica de esta cate- 
to del reino aragonés, y la necesidad de su protección queda en evidencia con las modificaciones de las tasas arancelarias del General decretadas en 1446: las entradas de hierro y acero por las fronteras aragonesas pasan a ser gravadas en un $10 \%$ de su valor, el doble del porcentaje que pagan casi todas las demás mercancías (Sesma Muñoz, 1976: 116).

El concurso de este proteccionismo, unido al incremento progresivo de la demanda vinculado a la mejora económica y demográfica general, que inicia su progreso precisamente en estos momentos, y, quizás, a la ralentización coetánea de otras áreas siderúrgicas consolidadas, que parecen acusar dificultades crecientes para el aprovisionamiento de combustible y mineral de calidad ${ }^{80}$ favorece en la segunda mitad del Cuatrocientos un periodo de florecimiento del sector férrico del Moncayo, que coincide con el despegue general de la minería europea (Sánchez Gómez, 1997: 12 y ss.). Nuestras fuentes lo reflejan medianamente bien. Hay diversas factorías en funcionamiento y nos consta fehacientemente la apertura de varias nuevas, que implican inversiones de cierto alcance, tanto en metálico como bajo la forma de jornales, derechos sobre aguas y montes etc. Son las ferrerías de Vozmediano y Agramonte, abiertas hacia mediados del Cuatrocientos o en algún momento no muy anterior, la de Jarque en 1488 y la - o las - de Trasmoz hacia el cambio de siglo, seguramente entre otras. El acicate definitivo viene dado por una espectacular alza de precios que tiene lugar sobre el $1500 .{ }^{81} \mathrm{Si}$ el hierro del Moncayo se vende en Zaragoza y Calatayud en el último tercio del Cuatrocientos, a tenor de los exiguos aunque muy coincidentes datos que hemos presentado, a un precio estable entre los 17 y 18 ss. j. el q. -14 en la más cercana Borja- ${ }^{82}$ en 1518 se valoraba en 28 ss. (Galé Casajús, 1999-2000: 256, doc. 37) y en 1552

goría férrica cuya magnitud desconocemos - y más de 200 qs.; bastante más que de hierro. Villanueva Morte, 2005: Vol. II, 338-339. Ya en 1401 la cofradía de los cuchilleros de Zaragoza solicitaba al rey que prohibiese a los dueños de forjas obrar con azero de Genova ni otro mal azero. El problema subsiste en 1423 en que las ordenanzas de la corporación prohíben el uso de los azeros clamados de Genova e de Lombardia. Falcón Pérez, 1997: 167 y 246, docs. 110 y 123.

80 El caso de la vecina Navarra es paradigmático, véase Mugueta Moreno, 2009: 23 y 29. En Cantabria la apertura de nuevos talleres baja de 22 en la primera mitad del s. XV a 2 en la segunda, Ceballos Cuerno, 2001: 267.

81 La tendencia es general, aunque por lo común con incrementos menos virulentos, en conexión con la fuerte y bien conocida inflación global que tiene lugar durante el periodo. Véase el ejemplo del hierro guipuzcoano en Díez de Salazar, 1983: Vol. I, 351 y ss.

82 Son cifras que se ajustan al valor medio de mercado en Aragón en este tiempo. El hierro vasconavarro que entraba en el reino en el centro del Cuatrocientos es apreciado en los puestos aduaneros de las Cinco Villas sobre los 14/15 ss. j. el q., Sesma Muñoz y Abella Samitier, 2013: 22-25; en la tabla de Zaragoza, después de ser transportado por el Ebro, entre los 15 y 20, Sesma Muñoz, 1982: 79. 
se pagaba, puesto en Zaragoza, a 41, como hemos visto para Añón (San Vicente Pino, 1988: Vol. I, 239-240, doc. 133). ${ }^{83}$ Con semejante ascenso, aun descontando el alza de costes, propia de una centuria inflacionaria como es el Quinientos, las cotas de beneficio debieron verse fuertemente incrementadas, empujando a que los establecimientos, a poco que acompañasen las condiciones de explotación, se mantuviesen en activo todo lo posible, aunque, por supuesto, siempre es posible rastrear excepciones y la paralización del taller de Trasmoz en 1518 es una buena muestra de ello.

Así pues, partiendo de las siete localizaciones geográficas documentadas para las últimas décadas medievales - Jarque, Purujosa, Añón, Trasmoz, Agramonte, Araviana y Vozmediano - y contando con que en alguna de ellas es admisible que hubiese más de un horno o taller - la de Trasmoz es la más probable - , podemos evaluar, desde la cautela, pues no en vano no tenemos más que noticias muy fragmentarias, que el Moncayo alberga, en el peor de los casos, no menos de cuatro o cinco ferrerías trabajando a la vez muy a finales del Cuatrocientos y, traspasado el umbral del siglo XVI, tras la inauguración del complejo de Trasmoz, una o dos más.

Todos estos ingenios utilizan, con toda certeza, la fuerza de la cinética fluvial y en un caso - el de Jarque - está contrastada documentalmente la dotación de fuelles mecánicos, barquinos. No hay que dudar que este recurso está generalizado en las factorías comarcanas pues, en su conjunto, el trabajo técnico, en todas sus categorías, está dominado masivamente por vizcainos, es decir, emigrantes muy recientes del País Vasco — sobre todo, a juzgar por los apellidos - , las comarcas limítrofes de Navarra o la cornisa cantábrica, ${ }^{84}$ regiones donde estas mejoras están difundidas desde la centuria anterior (Mugueta Moreno, 2009: 20-22). Esto implica una producción, cuando menos, considerable. Algunas de las noticias exhumadas así lo confirman: la factoría de Añón es capaz de

83 La escalada continúa durante toda la centuria: en 1568 el q. de hierro navarro se compra en Zaragoza a 50 ss. j., San Vicente Pino, 1988: Vol. I, 368-369, doc. 195. A fines del siglo XVI el procedente de Bielsa, igualmente en la capital del Ebro, a 84, Pallaruelo Campo, 1994: 157. Por supuesto, estamos hablando en términos muy simplificados, pues habría varios tipos de hierro, en función de usos, idoneidades - el hierro belsetano, por ejemplo, siempre se pagaba algo más que el común por su mayor ley-, etc. Pero bastan para reconocer la tendencia y su entidad.

84 Su condición de recién llegados es muy palpable a la hora de aportar bienes garantes para avalar las comandas que toman: casi siempre, semovientes, muy pocas veces, inmuebles, justo al revés de la pauta que rige para los nativos o los naturalizados. En las serranías ibéricas la emigración, en principio de carácter temporal, de mineros y ferrones procedentes de Vasconia se prolongó hasta el siglo XVIII, Benedicto Gimeno y Mateos Royo, 2013: 201-210. 
surtir 250 qs. anuales a un mercader de Calatayud en 1469 y otros 200 en 1471, mientras que la de Vozmediano, hacia 1489, se compromete a servir unos 500 al año en Borja, a un ritmo de 9 semanales, lo que, si hay que creer a su propietario, cumple con colmo. Y hay que significar que estas cifras no suponen necesariamente el total de la producción de esos establecimientos, como sabemos expresamente para el caso de Añón en 1469. Los montos de los arrendamientos de las ferrerías que conocemos apuntan en la misma dirección: el de Jarque - aunque no pasó de intención - se calculó sobre 150 qs. férricos anuales en 1488 y el de La Mata de Castilviejo en 324 y una arroba en 1511, una cantidad - insistoenorme para un compromiso de este tipo.

La producción de hierro media de una ferrería vasca en el siglo XVI, con la ventilación mecánica del horno ya plenamente incorporada, ha sido estimada por Díez de Salazar, 1983: Vol. I, p. 273, en un óptimo de entre 1.500-1.800 qs. de la medida local (equivalente a 49,2 kg) anuales, aunque en verdad a partir de datos muy heterogéneos. No obstante, teniendo en cuenta los muchos imponderables y factores distorsionadores potenciales - la mayor o menor abundancia de agua utilizable, la disponibilidad de carbón o de vena y su ley, el estallido de pleitos, los accidentes...-, que pueden hacer que una misma factoría arroje resultados notablemente dispares de un año para otro, el autor acaba rebajando el índice medio hasta los 1.250 qs. (unas 61,5 tn) de forma convencional. ¿Puede trasponerse este monto a los talleres del Moncayo? No puedo ofrecer seguridades, desde luego, pero podría ser, en líneas generales, perfectamente verosímil.

En la década de 1520 surge un pleito sobre el pago de los derechos de albalá y diezmo viejo que se pretende imponer a siete ferrerías hidráulicas situadas en el río Hoceseca, en el término de Molina de Aragón, que explotan los filones del otro gran distrito férrico de la cordillera Ibérica, el de Sierra Menera. Cronológica y cualitativamente pueden considerarse el paralelo más cercano disponible a las industrias del Moncayo, con las que guardan muchas concomitancias: aparte de su condición de ferrerías de interior enclavadas en el área geográfica de las serranías ibéricas, su origen se remonta a los años finales del siglo XV y fueron erigidas por vizcaínos, que son quienes, mayoritariamente, siguen regentándolas. El tributo que deben pagar estos establecimientos se calcula sobre la base de una producción, que es estimada por el demandante en 2.000 qs. anuales por forja, para cinco de ellas, y 1.667 para las dos restantes, cantidades muy discrepantes con las declaradas por los propietarios: los de las cinco primeras rebajan el volumen productivo a 887 qs. en conjunto, es decir a poco más de 175 qs. por taller. Considerando la naturaleza litigiosa de la fuente, obviamente am- 
bos puntos de vista están viciados. Para complicar un poco más las cosas, el fallo es confuso pues desciende a lo que debe pagar cada porcionero, aunque no abarca todos - la propiedad de las ferrerías, que ha pasado por diferentes alienaciones y transmisiones hereditarias, está muy fragmentada - . En suma: solamente contamos con datos más o menos fiables para un caso, el de la ferrería nueva de Checa, que da salida a 1.450 qs. anuales, según la sentencia, y más de 1.000 , según reconoce uno de los propietarios, supongo, en un momento de flaqueza. ${ }^{85}$ Otros datos comparativos que podemos evocar, aunque más alejados en el tiempo, correspondientes a un estadio tecnológico similar, son los de las minas del valle de Bielsa en la segunda mitad del Quinientos, que se mueven sobre los mismos valores: entre los 1.000 y los 1.500 qs. por ferrería (Pallaruelo Campo, 1994: 152).

Aceptando por tanto la estimación de Díez de Salazar como punto de partida, cabría introducir alguna matización. Hay que pensar con que ni siquiera sabemos a ciencia cierta el número de talleres activos, pues solo contamos con una estimación, y además con que, más allá de las incertidumbres comunes, existe una inseguridad relevante sobre una variable tan importante como es el aforo de agua hábil para las ferrerías castellanas del Moncayo, como veíamos más arriba. Lo más aconsejable, por tanto, es optar por la prudencia y conformarnos con un índice medio de 1.000 qs. Así pues, presuponiendo que las ferrerías del Moncayo a fines de la Edad Media contaban con barquines de forma normalizada, podemos lanzar, desde un punto de vista conservador, la hipótesis de que la producción de hierro del Moncayo alcanzaría globalmente un mínimo de en torno a 4.000 o 5.000 qs. por ejercicio (unas 200/250 tn) en el cierre del Cuatrocientos y un par de miles más, como poco (otras 100 tn adicionales), en el momento que comience su andadura el obrador de Trasmoz, en los primeros años del Quinientos. Este saldo se dirige, aparentemente, a subvertir en primera instancia las necesidades de los mercados interiores de las inmediaciones, por obvias razones de competitividad ${ }^{86}$ con preferencia — hasta donde sabemos - del

85 Cortés Ruiz, 1996, y Cortés Ruiz, 2003: 928-929. Aun siendo de la misma autoría y abordando el mismo suceso con la misma fuente, los datos vertidos en estos trabajos, más que coincidentes, son complementarios. Más información sobre este foco siderúrgico en Cortés Ruiz, 2003: 919-945.

86 En los mercados poco integrados las expensas del transporte tenían un peso importantísimo en el precio final. Cuando se trataba de vías terrestres, como sucede en la mayor parte de Aragón y el interior peninsular, podían suponer una pérdida de competitividad crucial. Véanse, a título de muestra, los gravosos costes de transferencia del hierro del valle de Bielsa, durante la segunda mitad del 
aragonés, que comprobamos que capta fracciones significativas de los rendimientos de los establecimientos sitos en el reino vecino. Es lógico, la red urbana aragonesa es más densa y desarrollada en las cercanías que su homóloga castellana e implica, por consiguiente, una mayor demanda. Por otra parte, no consta que los trabajos del metal tuvieran en el área soriana ningún tipo de especial desarrollo durante la Baja Edad Media y el siglo XVI ${ }^{87}$.

Estas conclusiones son importantes. Aunque las cifras de producción que hemos barajado resultan casi ridículas frente a las de las grandes áreas siderúrgicas del Cantábrico - Díez de Salazar, 1983: Vol. I, 273, calcula, solo para Guipúzcoa, entre 7.380 y más de 10.000 tn anuales para el arranque del Quinientos - , no cabe duda que, para la economía comarcal e incluso regional, suponen una inyección de dinamismo de fértiles consecuencias. Pensemos por un momento que, en números redondos, 5.000 qs. de hierro a un precio unitario de $20 \mathrm{ss}$. j., que podría ser el corriente sobre el 1.500 en Zaragoza o Calatayud, suman 100.000 ss., un importe nada despreciable.

En el ámbito específico de Aragón, si nuestros cálculos son correctos, solo la producción de la margen aragonesa del Moncayo, que podría ser la parte del león en estos momentos del total de la del macizo, supone rebajar de forma ostensible la subordinación a las importaciones exteriores, tan acusada anteriormente, favoreciendo el saldo comercial del reino. Y ello sin contar con los eventuales aportes de los otros distritos férricos aragoneses - el valle de Bielsa y el área de Albarracín y Sierra Menera - para los que carecemos, para esta cronología, de cualquier información.$^{88}$ En otro orden

Quinientos, en Pallaruelo Campo, 1994: 150-151 y 157-158. Teniendo que cargar con esta rémora, el metal belsetano - como seguramente el del Moncayo - se comercializaba eminentemente en los centros de consumo más cercanos: las comarcas del cuadrante nororiental del reino, desde Huesca hasta el Cinca, sin cruzar la línea del Ebro, aparte de en la ciudad de Zaragoza, la cual absorbía una importante fracción del total de la producción, Pallaruelo Campo, 1994: 155 y ss., y Nieto Callén, 1996: 489-490.

87 El ejemplo de la ciudad de Soria, el enclave urbano más importante de los contornos, es concluyente (Diago Hernando, 2009).

88 Para el foco pirenaico no contamos, para el Cuatrocientos, más que con unas pocas noticias de la salida de pequeñas cantidades de ferre de Bielsa por las aduanas de Monzón y Bielsa a mediados de siglo, Bielza de Ory et alii, 1986: 105. Aunque parece que la explotación continuó, las tinieblas que pasan a envolverla no aclaran hasta la segunda mitad del Quinientos, véase Pallaruelo Campo, 1994, y Nieto Callén, 1996. Respecto al núcleo del sur de Aragón, hay algunas citas a ferrerías en el área de Albarracín, muy vagas, de muy finales del siglo XV y principios del XVI, retrasándose las primeras referencias firmes hasta la década de 1520. Véase el estado de la cuestión que dibuja Villanueva Morte, 2005: Vol. II, 337. Verificado el desarrollo del sector al otro lado de la muga, en el señorío de Molina, donde podría haber doce ferrerías operativas en el tránsito de la época medieval a la moderna, según 
de cosas, la entrada de semejante volumen de materia prima en el mercado y la competencia resultante con el metal de otras procedencias debió ser un poderoso estímulo para todos los oficios relacionados con la manipulación del hierro, un segmento artesanal que en Aragón tiene tanto peso como tradición (Falcón Pérez, 1996: 366 y ss.) ${ }^{89}$; su eventual progresión es un tema que merecería ser explorado.

\section{Conclusiones}

Queda en evidencia que la industria férrica en el Moncayo se remonta, de forma probada, al siglo XIII, aunque es muy posible que sus raíces se retrotraigan, como mínimo, al siglo anterior. En origen, se trata de explotaciones muy primarias, aunque no carentes de interés, sostenidas por la población autóctona mediante procedimientos arcaicos, sin interferencias ni prácticamente inversiones de ningún tipo. Esta situación evoluciona en la segunda mitad del Doscientos, de la mano de un renovado y generalizado interés por la minería. El rey, la nobleza y hasta - podría ser - los simples particulares promocionan la aparición de nuevos establecimientos siderúrgicos que, aparentemente, tiene mucho mayor empaque que los del pasado. Es muy factible que incorporen ya las novedades de la siderurgia hidráulica - en concreto, el uso del martinete - , en sincronía con la inmensa mayoría de las demás regiones productoras peninsulares, con todo lo que ello supone en términos de mejora de la productividad. El sector férrico del Moncayo vive así, en estos momentos, dentro de su modestia, lo que parece su primer despegue de importancia desde la Antigüedad. Aunque no sabemos si se sostiene, pues a partir de fines del Doscientos nuestra información se corta de forma tan abrupta como, prácticamente, absoluta.

Tras un paréntesis de un siglo medio, la situación en el ecuador del Cuatrocientos parece extraordinariamente gris. Pero va a animarse en la segunda mitad de esa centuria, un periodo de expansión similar al del siglo XIII, pero más consistente: a caballo del 1500 el Moncayo cuenta con en torno a media docena de factorías en activo. Servidas mayoritariamente por emigrantes vizcainos que, con casi total seguridad, importan los proce-

Cortés Ruiz, 2003: 933, sería interesante profundizar en el tema.

89 Según esta autora el metal es la cuarta industria del reino, sólo por detrás de la textil, la del cuero y la construcción, id.: 374 . 
dimientos que rigen en su tierra natal, entre ellos el uso de fuelles mecánicos, avance tecnológico fundamental que incrementa espectacularmente los rendimientos, la producción del Moncayo debe alcanzar cotas interesantes a fines de la Edad Media y el Quinientos. Aunque, por supuesto, sus magnitudes no pueden compararse con las de las grandes áreas siderúrgicas del Cantábrico ${ }^{90}$ tiene su repercusión a nivel regional. Dirigida, en primera instancia, a cubrir las necesidades de los mercados interiores limítrofes y, especialmente, el aragonés, debe suponer un incremento muy visible de las cotas de autoabastecimiento. Esto significa que la idea - notablemente asentada - de que Aragón, como la meseta soriana, fue durante la Baja Edad Media y la Moderna un mero mercado de la siderurgia foránea, en primera instancia, vasconavarra y, supletoriamente, de procedencia mediterránea, debe revisarse. Sin negar su indudable importancia, a partir de lo expuesto, está claro que esa dependencia conoce, aun desde el punto de vista más crítico, fluctuaciones.

Pero tal vez la conclusión más importante es que la extracción e industria del hierro medievales y de la primera modernidad no son, en el Moncayo aragonés, como en el castellano, tan banales y retardatarias como se suponía. Reproduciendo con notable fidelidad - hasta donde hemos podido averiguar- los grandes flujos de avance y retroceso de la minería europea e integrando las novedades tecnológicas que iban sucediéndose, parece plausible que sin excesivas desviaciones cronológicas con respecto a la mayoría de los demás focos férricos hispanos, tuvieron su papel. Y, aunque sus resultados no podían competir en valor e interés con los del omnipotente sector agropecuario, resulta estimulante comprobar, por la diversificación que suponen, que aportaron su granito de arena a la economía del territorio, de forma notoria en ese periodo de recuperación y prosperidad que, arrancando de mediados del siglo XV, se prolonga a lo largo del Quinientos.

\section{Referencias bibliográficas}

ACERETE TEJERO, J.M. (2001), Estudio documental de las artes en la Comunidad de Calatayud en el siglo XVI, Calatayud, Centro de Estudios Bilbilitanos.

90 Para fines del Cuatrocientos hay entre 90 y 110 ferrerías en activo en Guipúzcoa, 50 en Vizcaya, unas 40 en Navarra, localizadas sobre todo en el escarpe atlántico, y entre 35 y 45 en Cantabria, Mugueta Moreno, 2013, 73-74. 
ALVIRA CABRER, M., e IBARRA Y OROZ, M.A. (2010), Pedro el Católico, Rey de Aragón y Conde de Barcelona (1196-1213). Documentos, testimonios y memoria histórica, Zaragoza, Institución Fernando el Católico (IFC).

ARCO, R. del (1916), «El famoso jurisperito del siglo XIII Vidal de Cañellas [sic], obispo de Huesca. Noticias y documentos inéditos (conclusión)», Boletín de la Real Academia de Buena Letras de Barcelona, 8/64, 508-521.

ASSO, I. de (1798), Historia de la Economía Política de Aragón, Zaragoza, Francisco Magallón.

BALBOA DE PAZ, J.A. (1990), Hierro y herrerías en el Bierzo pre-industrial, León, Diputación Provincial.

BENEDICTO GIMENO, E., y MATEOS ROYO, J.A. (2013), La minería aragonesa en la cordillera Ibérica durante los siglos XVI y XVII. Evolución económica, control político y conflicto social, Zaragoza, Centro de Estudios del Jiloca-Prensas Universitarias de Zaragoza.

BIELZA DE ORY, V., et alii (1986), Estudio histórico-geográfico del valle de Bielsa (Huesca), Huesca, Instituto de Estudios Altoaragoneses.

BILBAO BILBAO, L.M. (1987), «Introducción y aplicaciones de la energía hidráulica en la siderurgia vasca, siglos XIII-XVII», Studia historica. Historia moderna, $5,61-74$.

BLANCO TRÍAS, P.J. (1949), El Real Monasterio de Santa María de Veruela 11461946, Palma de Mallorca, Impr. Mossén Alcover.

BLÁZQUEZ, J.M. (1970), «Fuentes literarias griegas y romanas referentes a las explotaciones mineras de la Hispania romana», en VI Congreso Internacional de Minería. La Minería hispana e iberoamericana, Vol. I, León, Cátedra de San Isidoro, 117-150.

BLÁZQUEZ HERRERO, C., y PALLARUELO CAMPO, S. (1999), Maestros del agua, Zaragoza, Gobierno de Aragón.

CABANES PECOURT, A. (1985), El Libro Registro de Veruela, Anúbar, Zaragoza.

CANELLAS LÓPEZ, A. (1977): «Fuentes de los Anales de Zurita. El proceso de los monederos falsos de Tarazona de 1267», en Homenaje a Don José María Lacarra de Miguel en su jubilación del profesorado, Zaragoza, Anúbar, Vol. II, 263-277.

CARMONA PÉREZ, J.M., et alii (1989), «Estudio de las mineralizaciones de hierro de la vertiente septentrional del Moncayo», Turiaso, 9, 177-186.

CEBALLOS CUERNO, C. (2001), Arozas y ferrones: las ferrerías de Cantabria en el Antiguo Régimen, Santander, Universidad de Cantabria.

CHACON, C. (1989), «La dehesa del Moncayo, parque natural y espacio turístico», Turiaso, 9, 829-836.

CORBERA MILLÁN, M. (2001), La siderurgia tradicional en Cantabria, Oviedo, Septem. 
CORTÉS RUIZ, M.E. (1996), «Las ferrerías del río Hoceseca (Señorío de Molina) a fines del siglo XV», en Actas de las I Jornadas sobre Minería y Tecnología en la Edad Media Peninsular, León, Fundación Hullera Vasco-Leonesa, 475-485.

- (2003), Articulación jurisdiccional y estructura socioeconómica en la comarca de Molina de Aragón a lo largo de la baja Edad Media, Tesis doctoral leída en la Universidad Complutense en 2003, accesible vía web en http://eprints.ucm. es/2526/ (fecha de la consulta: 03-07-2015).

DIAGO HERNANDO, M. (2009), «La ciudad de Soria como centro manufacturero durante el período bajomedieval», Espacio, tiempo y forma. Serie III, Historia medieval, 22, 65-89.

DÍEZ DE SALAZAR, L.M. (1983), Ferrerías de Guipúzcoa, siglos XIV-XVI, San Sebastián, Haranburu.

FALCÓN PÉREZ, M.I. (1996), «La manufactura del hierro en Aragón en los siglos XIV y XVI», en Actas de las I Jornadas sobre Minería y Tecnología..., 363-383.

FALCÓN PÉREZ, M.I. (1997), Ordenanzas y otros documentos complementarios relativos a las Corporaciones de oficio en el Reino de Aragón en la Edad Media, Zaragoza, IFC.

GALÉ CASAJÚS, E.I. (1997-98), «Aportación documental para el establecimiento de la biografía de Pedro Manuel de Urrea, señor de Trasmoz (I)», Turiaso, 14, 225-302.

- (1999-2000), «Aportación documental para el establecimiento de la biografía de Pedro Manuel de Urrea, señor de Trasmoz (II)», Turiaso, 15, 229-286.

GARCÍA HERRERO, M. ${ }^{a}$ Carmen (1983), «El tráfico comercial entre Aragón y Castilla, a través de Calatayud, a mediados del siglo XV», en Primer Encuentro de Estudios Bilbilitanos, Calatayud, Centro de Estudios Bilbilitanos, Vol. II, 166-175.

- (1984), «La aduana de Calatayud en el comercio entre Castilla y Aragón a mediados del siglo XV», En la España Medieval, 4, 363-390.

GARCÍA MANRIQUE, E. (1960), Las comarcas de Borja y Tarazona y el Somontano del Moncayo. Estudio geográfico, Zaragoza, Instituto Juan Sebastián Elcano.

GARCÍA MARCO, F.J. (1993), Las comunidades mudéjares de Calatayud en el siglo $X V$, Calatayud, Centro de Estudios Bilbilitanos.

GARCÍA MARCO, F.J., MOTIS DOLADER, M.A. (2001), «Estructura señorial de la comarca de Aranda durante la Edad Media», en J. Hernández, J. Millán y A. Serra, A. (coords.), Comarca del Aranda, Zaragoza, Departamento de Presidencia y Relaciones Institucionales [del Gobierno de Aragón].

GERRARD, C. (2003), Paisaje y señorío. La casa conventual de Ambel (Zaragoza), Zaragoza, Centro de Estudios Borjanos.

GONZÁLEZ CARVAJAL, T. (1832), Registro y relación general de minas de la Corona de Castilla. Primera parte, Madrid, Imprenta de Miguel de Burgos.

GONZÁLEZ PÉREZ, C. (1994), A producción tradicional do ferro en Galicia. As grandes ferrerías da provincia de Lugo, Lugo, Diputación Provincial. 
GUAL CAMARENA, M. (1970), «El hierro en el Medievo hispano», en VI Congreso Internacional de Minería. La Minería hispana e iberoamericana, Vol. I, León, Cátedra de San Isidoro, 275-292.

GUTIÉRREZ LÓPEZ, A. (2005), Un viaje a las fortificaciones medievales de Tarazona y el Moncayo [catálogo], Zaragoza, Diputación Provincial.

HUICI MIRANDA, A., y CABANES PECOURT, M.D. (1976), Documentos de Jaime I, Valencia, Anúbar.

IRANZO MUÑÍO, M.T., y ORTEGA ORTEGA, J.M. (2011), «Disciplina agraria y reorganización del poblamiento bajomedieval en el territorio de la Comunidad de aldeas de Daroca», Aragón en la Edad Media, 22, 67-126.

KIVIHARJU, J. (1989), Los Documentos Latino-Romances del Monasterio de Veruela 1157-1301. Edición, estudio morfosintáctico y vocabulario, Helsinki, Soumalainen Tiedeakatemia.

LABAÑA, J.B. (1895), Itinerario del Reino de Aragón, Zaragoza, Diputación Provincial.

LARA IZQUIERDO, P. (1984), Sistema aragonés de pesos y medidas . La metrología histórica aragonesa y sus relaciones con la castellana, Zaragoza, Guara.

LARRUGA BONETA, E. (1792), Memorias políticas y económicas sobre los frutos, comercio, fábricas y minas de España, T. XXI, Madrid, Imprenta de Antonio Espinosa, [reed. facsímil, Zaragoza, IFC, 1995].

LEDESMA RUBIO, M.L. (1991), Cartas de población del Reino de Aragón en los siglos medievales, Zaragoza, IFC.

LORRIO, A.J., GÓMEZ RAMOS, P., MONTERO, I., y ROVIRA, S. (1999), «Minería y metalurgia celtibérica», en F. Burillo Mozota (coord.), IV Simposio sobre los Celtíberos. Economía, Zaragoza, IFC, 161-180.

MARICHALAR, C. (1934), Colección diplomática del rey don Sancho VIII (el Fuerte) de Navarra, Pamplona, Aramburu.

MATA-PERELLÓ, J.M. (1989), «Introducción al estudio de las mineralizaciones del Moncayo y de sus alrededores», Turiaso, 9, 163-174.

MONESMA MOLINER, E. (1993), «Carbón vegetal», Temas de antropología aragonesa, 4, 60-74.

MONTERDE Y LÓPEZ DE ANSÓ, M. (1788), Ensayo para la descripción geográfica, física y civil del corregimiento de Calatayud, 1788, introd. y transcripción de J.M. Sánchez Molledo, Calatayud, Centro de Estudios Bilbilitanos, 1999.

MUGUETA MORENO, I. (2009), «La primera industrialización en Navarra: las ferrerías en la Baja Edad Media», Huarte de San Juan. Geografía e historia, 16, 9-58.

- (2010), «El comercio de hierro entre Navarra y Aragón (1349-1387)», en E. Ramírez Vaquero y R. Salicrú i Lluch (coords.), Cataluña y Navarra en la Baja Edad Media, Pamplona, Universidad Pública de Navarra, 165-224.

MUGUETA MORENO, I. (2013), «Les territoires de la sidérurgie médiévale au Pays Basque et en Navarre», en J.M. Minovez, C. Verna y L. Hilaire-Pérez, Les indus- 
tries rurales dans l'Europe médiévale et moderne, Toulouse, Presses Universitaires du Mirail, 63-76.

NAVARRO ESPINACH, G. (2009), «La formación de los señoríos del condado de Aranda», en M.J. Casaús Ballester, M.J. (ed.), El Condado de Aranda y la Nobleza Española en el Antiguo Régimen, Zaragoza, IFC, 65-84.

NIETO CALLÉN, J.J. (1996), «El proceso sidero-metalúrgico altoaragonés: los valles de Bielsa y Gistaín en la Edad Moderna (1565-1800)», Llull, 37, 471-507.

ORTEGA ORTEGA, J.M. (2008), «Consideraciones sobre la explotación del hierro en Sierra Menera (Teruel) durante época andalusí», en A. Cantó García, P. Cressier, y P. Grañeda Miñón (eds.), Minas y metalurgia en al-Andalus y en el Magreb occidental: explotación y poblamiento, Madrid, Casa de Velázquez, 95-122.

PALACIOS MARTÍN, B. (1977), «El tesoro real de la Corona aragonesa y su función económica. Época de formación», en Homenaje a Don José María Lacarra..., Vol. II, 279-305.

PALLARUELO CAMPO, S. (1994), «El hierro en los valles de Bielsa y Gistau en el s. XVI», Revista del Centro de Estudios de Sobrarbe, 1, 135-161.

PÉREZ VIÑUALES, P. (1996), «La actividad de la industria del hierro en la comarca del bajo Jalón (Zaragoza) en el siglo XV: tipología documental», en Actas de las I Jornadas sobre Minería y Tecnología..., 535-542.

RODRÍGUEZ LAJUSTICIA, F.S. (2005), «Noticias documentales sobre el desaparecido castillo de Ferrellón (siglos XIII-XIV)», en Actas del III Congreso de Castellología Ibérica, Guadalajara, Asociación Española de Amigos de los Castillos y Diputación de Guadalajara, 573-588.

- (2008), «Nuevos datos sobre una antigua fortaleza del Moncayo: el castillo de Ferrellón», Castillos de España, 149 (2008), 21-26

- (2010), El dominio del monasterio cisterciense de Santa María de Veruela desde su fundación hasta 1400, Zaragoza, IFC.

ROMANO, D. (1983), Judíos al servicio de Pedro el Grande de Aragón (1276-1285), Barcelona, CSIC, Universidad.

RUBIO SEMPER, A (2006), Libro de la Pecha de la villa de Ateca, Zaragoza, IFC.

SAN VICENTE PINO, A. (1988), Instrumentos para una historia social y económica del trabajo en Zaragoza en los siglo XV al XVIII, Zaragoza, Real Sociedad Económica de Amigos del País.

SÁNCHEZ CASABÓN, A.I. (1995), Alfonso II Rey de Aragón, Conde de Barcelona y Marqués de Provenza. Documentos (1162-1196), Zaragoza, IFC.

SÁNCHEZ GÓMEZ, J. (1990), De minería, metalúrgica y comercio de metales. La minería no férrica en el reino de Castilla (1450-1610), Salamanca, Universidad de Salamanca e Instituto Tecnológico Geominero de España.

- (1997), Minería y metalurgia en la Edad Moderna, Madrid, Akal.

SANCHO I PLANAS, M. (2011), «El hierro en la Edad Media. Desarrollo social y tecnología productiva», Anuario de Estudios Medievales, 41, 645-671. 
SANZ, J.M. (1935), El Moncayo, Zaragoza, 1935 [reed. Zaragoza, El Día de Aragón, 1986].

SANZ ARTIBUCILLA, J.M. (1930), Historia de la fidelísima y vencedora ciudad de Tarazona, Madrid, Imprenta de Estanislao Maestre, 1930.

SANZ PÉREZ, E., et alii (2001), «La minería antigua del Moncayo: un horno de fundición de hierro en el Estrecho de Araviana, sierra de Toranzo (Ólvega)», Celtiberia, 95, 33-63.

SARASA SÁNCHEZ, E. (1977), «El señorío jurisdiccional de Trasmoz en el siglo XV», en Homenaje a Don José María Lacarra ..., op . cit., Vol. IV, 79-93.

SESMA MUÑOZ, J.A. (1976), «Las Generalidades del Reino de Aragón. Su organización a mediados del siglo XV», Anuario de Historia del Derecho Español, 46, 393-467 [utilizo la reed. de este texto incluida en SESMA MUÑOZ, J.A., Revolución comercial y cambio social. Aragón y el mundo mediterráneo (ss. XIV-XV), Zaragoza, Prensas de la Universidad, 2013, 95-115].

- (1982), Transformación social y revolución comercial en Aragón durante la Baja Edad Media, Madrid, Fundación Juan March [utilizo la reed. de este texto incluida en id., 43-91].

SESMA MUÑOZ, J.A. (1995), «Aspectos económicos», en A. Ubieto Arteta (dir.), Enciclopedia temática de Aragón. Historia I: de la Prehistoria al fin de la Edad Media, Zaragoza, Prensa Diaria Aragonesa.

- (2009), «Del Cantábrico al Mediterráneo: la vía fluvial del Ebro», en J.A. Sesma Muñoz y C. Laliena Corbera (coords.), Crecimiento económico y formación de mercados en Aragón en la Edad Media (1200-1350), Zaragoza, Universidad, 25-61.

SESMA MUÑOZ, J.A., coord. (1992), Un año en la historia de Aragón, 1492, Zaragoza, Caja de Ahorros de la Inmaculada.

SESMA MUÑOZ, J.A., y ABELLA SAMITIER, J. (2013), Las aduanas de las Cinco Villas a mediados del s. XV, Zaragoza, Universidad.

SESMA MUÑOZ, J.A., y LÍBANO ZUMALACÁRREGUI, Á. (1982), Léxico del Comercio Medieval en Aragón (siglo XV), Zaragoza, IFC.

SOLORZANO TELECHEA, J.A. (2006), «La producción y comercialización del hierro en las Cuatro Villas de la Costa de la Mar. Aportación al estudio de la industria siderúrgica en la Corona de Castilla en la Baja Edad Media», Studi Medievali, XLVII, fasc. 1, 71-110.

UBIETO ARTETA, A. (1991), Aragón, comunidad histórica (atlas didáctico-histórico), Zaragoza, Departamento de Cultura y Educación, 1991.

UBIETO ARTETA, A. (1984), Historia de Aragón. Los pueblos y los despoblados, Zaragoza, Anúbar.

URTEAGA ARTIGAS, M.M. (1996), «Siderurgia medieval en Guipúzcoa. Haizeolas, ferrerías masuqueras y ferrerías mazonas», en Actas de las I Jornadas sobre Minería y Tecnología..., 543-558. 
UTRILLA UTRILLA, J.F., LALIENA CORBERA, C., y NAVARRO ESPINACH, G. (2006), «Los recursos naturales y su transformación en los Pirineos aragoneses durante la Edad Media», en A. Catafau (coord.), Les ressources naturelles des Pyrénées du Moyen Âge à l'époque moderne. Exploitation, gestion, appropiation. Actes du Congrès International Resopyr 1, Perpignan, Presses Universitaires.

VERNA, C. (2001), Le temps des moulines: fer, technique et société dans les Pyrénées centrales (XIIIe-XVIe siècles), Paris, Publications de la Sorbonne.

- (2011), «Innovations et métallurgies en Méditerranée Occidentale (XIIIe-XVe siècles)», Anuario de Estudios Medievales, 41, 623-644.

VILLANUEVA MORTE, C. (2005), Movilidad social y relaciones económicas entre los reinos de Aragón y Valencia en el siglo XV [Recurso electrónico], Zaragoza, Universidad.

VV.AA. (1994), La minería de Aragón, Zaragoza, Gobierno de Aragón.

XIMÉNEZ DE ARAGUÉS, J. (1630), Discurso del Oficio de Bayle General de Aragón. En que se declaran muchos Fueros, y Actos de Corte de dicho Reyno; y se trata de diversas Regalias... que pertenecen a la Baylia general, Zaragoza, Juan de Lanaja y Quartanet.

\section{Apéndice documental}

1488, abril, 12. Épila.

Concordia entre Lope Ximénez de Urrea, conde de Aranda, y Julián Navarro, ferrero vizcaíno, para la búsqueda de minas de hierro en los dominios condales y la construcción de una ferrería en Jarque.

APNZ, Antón de Abiego, notario de Épila, 1488, cuadernillo 9, ff. 30r-31v.

/30r/ Yeshus.

Capitoles y concordia fechos entre el muy egregio senyor don Lope Ximenez d'Urrea, conde de Aranda, de la una parte, y Julian Navarro, vizcayno, ferrero, de la otra parte, en et sobre las ferrerias debaxo contenidas que se han de fazer en la tierra del dicho senyor conde.

Primeramente, es concordado entre las dichas partes que el dicho Julian Navarro, a su cargo y despesa, haya de buscar mina y vena de fierro en la tierra e terminos del dicho senyor conde y aquella hubrir fasta de aquella liberament se pueda sacar y cabar la tierra y vena dispuesta para fazer el fierro. 
Item, es concordado entre las dichas partes que, luego e de continent que la dicha mina e vena sera trobada y abierta, que de aquella se pueda sacar la tierra dispuesta para fazer el fierro, el dicho senyor conde, a su despesa, haya de obrar y fabricar en el termino y tierra suyos una casa y ferreria, con todos sus pertrechos y adrecos necessarios para fazer el dicho fierro y molient y corrient.

Item, es concordado entre las dichas partes que, luego que la dicha ferreria sera fecha, el dicho senyor conde haya de arrendar al dicho Julian Navarro la dicha ferreria por tiempo de seys anyos, con/30v/taderos del dia que la dicha ferreria comencara a labrar y obrar en delant, y por precio en cada un anyo de cient y cinquanta quintales de fierro, pagaderos cada una semana tres quintales.

Item, es concordado entre las dichas partes que, por ayuda del busquar de la mina, el dicho senyor conde haya de tomar en conto en una anyada de la dicha arrendacion al dicho Julian Navarro vint y cinquo florines d'oro, la qual anyada sea a boluntat del senyor conde.

Item, es concordado entre las dichas partes que, durant el tiempo de la dicha arrendacion, el dicho Julian Navarro pueda cortar fusta y fazer carbon en los montes del dicho senyor conde para lo que sera necessario a la dicha ferreria.

Item, es concordado entre las dichas partes que, al fin de la dicha arrendacion el dicho Julian Navarro, haya de dexar la dicha ferreria molient y corrient, segunt la tomo.

\section{(F.31r en blanco)}

$131 \mathrm{v} /$ XII aprilis anno M CCCC LXXXVIII, en Epila, el muy egregio senyor don Lope Ximenez d'Urrea, conde de Aranda, de la una part, et Julian Navarro, vizcayno, ferrero, de la otra part, daron, livraron y firmaron la present cedula de capitoles en poder de mi, Anthon Aviego, notario infrascripto, prometiendo y obligandose tener y complir lo contenido en aquella etc., es a saber, cada uno a lo que por virtut de aquella es tenido etc., dius obligacion de sus bienes etc., large.

Testes: el honrado Ferrando de Montesa, mercader, ciudadano de Caragoca, et Sthevan de Poma, scudero, habitant en la dicha villa de Epila.

1488, junio, 21. Épila.

Nueva concordia entre Lope Ximénez de Urrea, conde de Aranda, y Julián navarro, ferrero vizcaíno, sobre lo mismo. 
APNZ, Antón de Abiego, notario de Épila, 1488, cuadernillo 9, ff. 43r-44v. /43r/ Capitoles y concordia fechos entre el muy egregio senyor don Lope Ximenez d'Urrea, conde de Aranda, de la una parte, y Julian Navarro, vizcayno, ferrero, present en el lugar de Exiarch, de la otra parte, en et sobre las ferrerias debaxo contenidas, las quales el dicho Julian Navarro ha de fazer en la tierra del dicho senyor conde.

Primeramente, es concordado entre las dichas partes que el dicho Julian Navarro, a su cargo y despesa, excepto la ayuda que el dicho senyor conde de part de baxo le ha de fazer, sea tenido obrar, levantar y fabricar una casa y ferreria devidament, en lugar dispuesto, dentro los terminos del lugar de Exiarch, que es del dicho senyor conde, la qual casa e ferreria haya de comencar de continent que la mina y vena de fierro debaxo contenida sera trobada y abierta, segunt de iuso se contiene, la qual casa e ferreria el dicho Julian Navarro haya de fazer y levantar de buena y devida altaria, es a saber: el cimiento fasta dos palmos enant de la carra (sic.) de la tierra, de argamasa, y de alli arriba de buena tapia cubierta de buena fusta, bien y como deve estar, a conoscimiento de maestros, por forma que en la dicha casa e ferreria haya habitacion conviniente para el maestro de la dicha ferreria y a su conpanya, y disposicion buena donde labrar el fierro, y donde sten los pertrechos para la dicha ferreria nescessarios.

/43v/ Item, es concordado entre las dichas partes que el dicho Julian Navarro haya de busquar mina y vena de fierro, a toda despesa suya, en la tierra y terminos del dicho senyor conde, y la dicha mina ubrir, fasta [que] de aquella se pueda liberament saquar y cabar la tierra dispuesta para fazer el dicho fierro.

Item, es concordado entre las dichas partes que el dicho Julian Navarro, a su cargo y despesa, haya de fazer los barquinos, çobra, machos, tenacas y otros qualesquiere pertrechos y ferramienta para la dicha ferreria nescessarios.

Item, es concordado entre las dichas partes que, para ayuda de las sobredichas cosas, el dicho senyor conde haya de dar al dicho Julian Navarro dos mil sueldos jaqueses en contantes y mas cient y trenta peones.

Item, es concordado entre las dichas partes que' 1 dicho Julian Navarro pueda cortar la fusta franqua que nescessaria sera para la obra de la dicha casa y ferreria en los montes de los lugares de Aranda, Exiarque, Mesones y Tierga y las ruedas en la Mata.

/44r/ Item, es concordado entre las dichas partes que, si fusta alguna havra nescessaria o querra el dicho Julian Navarro cortar en la guerta de los lugares 
del dicho senyor, que aquella sea a cargo del dicho Julian Navarro y la haya el de comprar y egualarse con aquel de quien sera.

Item, es concordado entre las dichas partes que la fusta que el dicho Julian Navarro havra menester y cortado havra para la obra de la dicha casa y ferreria, que el dicho senyor conde haya, a su despesa, fazer traher la dicha fusta de donde cortada sera fasta la dicha casa y ferreria y, assimesmo, toda la ferramienta que el dicho Julian Navarro para la dicha ferreria fecho havra.

Item, es concordado entre las dichas partes que el dicho senyor conde haya de fazer, a su despesa, el açut y abrir la cequia que seran nescessarias para que benga el agua a la dicha ferreria y pueda moler y andar aquella devidamente.

Item, es concordado entre las dichas partes que el dicho Julian Navarro haya de tener la dicha casa y ferreria dos anyos franquos, sin pagar ni responder cosa alguna por razon de aquellas, contaderos del dia que la dicha ferreria comencara ad andar y obrar, y todo y qualesquiere $/ 44 \mathrm{v} /$ fierro que en la dicha ferreria durant los dichos dos anyos se obrara, sea franquo y propio del dicho Julian Navarro.

Item, es concordado entre las dichas partes que, acabados los dichos dos anyos, el dicho Julian Navarro haya de dexar la dicha casa e ferreria, sinse empacho alguno, al dicho senyor conde, molient y corrient, devidamente, con todos los barquinos, çobra, machos, tenacas, ferramienta y pertrechos de aquella et que ad aquella seran nescessarios.

Die XXI junii anno M CCCC LXXXVIII, en la villa de Epila, el muy egregio senyor don Lope Ximenez d'Urrea, conde de Aranda, de la una part, et Julian Navarro, ferrero vizcayno, habitant de present en el lugar de Exiarque, de la otra part, etc. las ditas partes daron, livraron y firmaron la present cedula de capitoles en poder de mi, Anthon de Aviego, notario infrascripto, prometiendo tener y complir aquella, dius obligacion de sus personas y bienes, etc. large, con renunciacionibus, submission de judge, etc. y las clausulas nescessarias.

Testes: los honrados Ferrando Montesa, mercader, ciudadano de Caragoca, et Johan Ferrandez de Moros, scudero de casa del dicho senyor conde. 